\title{
Review \\ Review: The Effects of Supersonic Aviation on Ozone and Climate
}

\author{
Sigrun Matthes ${ }^{1, *} \mathbb{D}$, David S. Lee ${ }^{2}$, Ruben Rodriguez De Leon ${ }^{2}$, Ling Lim ${ }^{2} \mathbb{D}$, Bethan Owen ${ }^{2}$, Agnieszka Skowron ${ }^{2}$, \\ Robin N. Thor ${ }^{1}$ a and Etienne Terrenoire ${ }^{3}$
}

1 Deutsches Zentrum für Luft- und Raumfahrt, Institut für Physik der Atmosphäre, Oberpfaffenhofen, 82334 Wessling, Germany; robin.thor@dlr.de

2 Faculty of Science and Engineering, Manchester Metropolitan University, Manchester M15 6BH, UK; D.S.Lee@mmu.ac.uk (D.S.L.); r.deleon@mmu.ac.uk (R.R.D.L.); 1.lim@mmu.ac.uk (L.L.); B.Owen@mmu.ac.uk (B.O.); a.skowron@mmu.ac.uk (A.S.)

3 ONERA, DMPE, Université Paris Saclay, F-91123 Palaiseau, France; etienne.terrenoire@onera.fr

* Correspondence: Sigrun.Matthes@dlr.de

check for updates

Citation: Matthes, S.; Lee, D.S.; De Leon, R.R.; Lim, L.; Owen, B.; Skowron, A.; Thor, R.N.; Terrenoire, E. Review: The Effects of Supersonic Aviation on Ozone and Climate. Aerospace 2022, 9, 41. https:// doi.org/10.3390/aerospace 9010041

Academic Editor: Judith Rosenow

Received: 26 November 2021 Accepted: 28 December 2021 Published: 15 January 2022

Publisher's Note: MDPI stays neutral with regard to jurisdictional claims in published maps and institutional affiliations.

Copyright: (c) 2022 by the authors. Licensee MDPI, Basel, Switzerland. This article is an open access article distributed under the terms and conditions of the Creative Commons Attribution (CC BY) license (https:// creativecommons.org/licenses/by/ $4.0 /)$.

\begin{abstract}
When working towards regulation of supersonic aviation, a comprehensive understanding of the global climate effect of supersonic aviation is required in order to develop future regulatory issues. Such research requires a comprehensive overview of existing scientific literature having explored the climate effect of aviation. This review article provides an overview on earlier studies assessing the climate effects of supersonic aviation, comprising non- $\mathrm{CO}_{2}$ effects. An overview on the historical evaluation of research focussing on supersonic aviation and its environmental impacts is provided, followed by an overview on concepts explored and construction of emission inventories. Quantitative estimates provided for individual effects are presented and compared. Subsequently, regulatory issues related to supersonic transport are summarised. Finally, requirements for future studies, e.g., in emission scenario construction or numerical modelling of climate effects, are summarised and main conclusions discussed.
\end{abstract}

Keywords: aviation climate impact; supersonic aviation; climate change; ozone; non- $\mathrm{CO}_{2}$ climate effects

\section{Introduction}

The development of civil supersonic transport (SST) aircraft has been pursued since the late 1960s and 1970s and can be traced back to the late 1950s. At the same period, concerns were expressed that aircraft emissions of nitrogen oxides $\left(\mathrm{NO}_{\mathrm{x}}\right.$, where $\left.\mathrm{NO}_{\mathrm{x}}=\mathrm{NO}+\mathrm{NO}_{2}\right)$ might impact the stratospheric ozone layer [1-3]. The emissions from aviation trigger changes in atmospheric processes and chemistry that lead to a radiative imbalance, a radiative forcing (RF) change, e.g., [4-8]. The radiative impacts show a strong vertical dependence in the atmosphere hence becoming highly relevant for supersonic aviation, occurring at different altitudes to conventional subsonic air traffic. To measure the radiative impact of supersonic aviation, one can rely on the concept of the changes induced to the RF in the atmosphere, which drives a climate change as measured by, e.g., global mean surface temperature. In earlier studies, the environmental impact of supersonic aviation was assessed using these two metrics: RF [4,9-11] and surface temperature change $[4,9,12]$. RF is a measure of the perturbation of the Earth-atmosphere energy budget for the time period between 1750 and the present day. This imbalance results from changes in concentration of trace gases and particles in the atmosphere and other effects such as changed albedo and is measured in units of watts per square metre $\left(\mathrm{W} \mathrm{m}^{-2}\right)$ at the top of the atmosphere or at the tropopause level. RF further acts as a predictor of changes in the surface temperature. The positive $\mathrm{RF}$ values are associated with global warming, the negative with global cooling.

On the regulatory side, the International Civil Aviation Organization (ICAO) was active in collecting information and knowledge on emissions and associated impacts with a particular focus on environmental and climate impacts within the Committee on 
Aircraft Engine Emissions (CAEE) [13-15]. There have been many studies over the course of the last 50 years (see Section 2 for a detailed history). More recently, development of SST technologies was accompanied by the investigation of possible negative impacts on the environment and the atmosphere, triggering research in European aeronautics research projects $[9,12]$. Although efforts to develop a large commercial SST waned since the late 1990s, there has been recent interest in developing both supersonic business jets and a smaller supersonic airliner [16]. A large body of scientific literature exists, but a systematic review of more recent results, comprising an evaluation of concepts for emission inventory generation, major assumptions on engine technology, route network and fleet developments as well as concepts applied in order to estimate climate impact of future SST air transport is currently lacking. Hence, the objective of this review paper is (1) to describe the historic context of supersonic aviation, (2) to present and review scientific understanding on physical and chemical processes determining the overall climate effect of supersonic aviation, (3) to present concepts of physical climate metrics in order to assess the climate effect of supersonic aviation while reviewing underlying assumptions and (4) to provide an overview on regulatory aspects applying to supersonic aviation, as well as (5) summarise key findings and recommendations which should be considered in future climate impact assessment studies.

This review paper was developed from within the European H2020 "SENECA" ((LTO) noiSe and EmissioNs of supErsoniC Aircraft) project. This European project aims to develop a deepened understanding and detailed modelling of emissions, landing/take-off (LTO) noise and the global environmental impact of supersonic aircraft. Within the overall workplan, one specific objective is to quantify a range of climate impacts of supersonic aviation for SST platforms to be explored achieved by numerical simulations with climatechemistry models (CCMs), climate response and contrail models. As an initial workflow, this assessment will establish the basis for defining numerical modelling studies that will facilitate the investigation of the climate impact of future SST fleets, as well as strengthening the perspective on the necessary regulations for novel supersonic aircraft.

\section{Historical Context}

The history of the development of a proposed civil SST aircraft can be traced back to the late 1950s when several countries including the UK/France, the USA and the Soviet Union were working on supersonic aircraft design. In Europe, the Anglo-French development of Concorde is well documented and, indeed, is the only programme that resulted in a long-term civil supersonic service. The only other civil supersonic aircraft developed was the Tupolev Tu-144, which only saw 1 year's active civilian transport service (within the USSR) after a chequered history of two catastrophic crashes: one at the Paris airshow in 1973 and another in the USSR in 1978.

In the US, an SST development programme was started in 1963, receiving submissions from Boeing and Lockheed. However, in Spring 1971, the US House of Representatives voted to close the SST development programme because of rising costs and concerns over noise, principally the sonic boom.

Discussion of potential stratospheric $\mathrm{O}_{3}$ depletion by a fleet of SSTs predated the closure of the US SST programme [17], although they were not necessarily connected. In July 1970, a conference entitled "Study of Critical Environmental Problems" (SCEP) was held in the US, sponsored by the Massachusetts Institute of Technology. One of the key discussions focused upon the potential effects of an SST fleet on the stratosphere. The group concluded that $\mathrm{O}_{3}$ depletion by water vapour emissions in the stratosphere would be insignificant and emissions of nitrogen oxides $\left(\mathrm{NO}_{\mathrm{x}}\right)$ would have a negligible effect [18]. This was despite an article claiming that a fleet of 500 SSTs would reduce the average $\mathrm{O}_{3}$ amount by a few percent from the water vapour emitted [19].

SCEP's conclusions regarding the role of SST $\mathrm{NO}_{x}$ emissions on stratospheric $\mathrm{O}_{3}$ were criticized by Harold S. Johnston, a chemist working at the University of California at Berkeley. Using the newly developed understanding of the role of $\mathrm{NO}_{x}$ in $\mathrm{O}_{3}$ destruction 
developed by Paul Crutzen [20], Johnston published a paper in August 1971 in Science, showing how a fleet of SSTs might significantly deplete stratospheric $\mathrm{O}_{3}$ [1]. In October of the same year, Crutzen went on to explain the chemical mechanisms of $\mathrm{NO}_{x}$ catalysed $\mathrm{O}_{3}$ destruction [21]. Crutzen, using his data, then published another article in April 1972 suggesting, like Johnston, that a fleet of SSTs might result in significant catalytic destruction of $\mathrm{O}_{3}$ by $\mathrm{NO}_{x}$ [2]. These important scientific events took place at the same time as the US SST development programme was terminated.

In 1972, another symposium "The Study of Man's Impact on Climate" (SMIC) was held, in preparation as input to the 1972 United Nations Conference on the Human Environment. This symposium likewise drew attention to the potential effects of SSTs on the stratosphere [22]. Other reports around this period (1971-1973) of interest were published by: the Commerce Technical Advisory Board [23]; the Australian Academy of Sciences [24]; and the Report to the House Science and Astronautics Committee [25]. The SMIC conference was noteworthy in that ecological impacts of climate were discussed. In this context, the testimony of McDonald to the US House tied SST emissions to increases in skin cancer incidence. Biological effects of increased ultraviolet (UV) radiation were reviewed by the US National Academy of Sciences (NAS) [26].

Although the US had terminated the SST development programme before the paper of [1], the growing concern over potentially significant $\mathrm{O}_{3}$ depletion resulted in the US Congress in September 1971 establishing a major research programme, the US "Climatic Impact Assessment Program" (CIAP) [27]. A factor in the initiation of this research programme was the ongoing development of SSTs in Europe and the Soviet Union (Concorde and Tupolev Tu-144).

Much of the basic research was lacking, and extensive research programmes on the stratosphere and aircraft emissions were initiated. CIAP, notably, was the first major integrated assessment programme, in that it investigated cause, effect and societal consequences. The study was completed by December 1974 with the summary report [28] being delivered to Congress in 1975.

The basic science outputs of the CIAP programme were extensive and advanced our knowledge of the stratosphere significantly [29]. However, the executive summary of the summary report, "CIAP Report of Findings" was the cause of some controversy both within and without the scientific community. It was claimed that it was misleading, effectively "toning down" the conclusions regarding the potential effects of an SST fleet on stratospheric $\mathrm{O}_{3}$ depletion ([30] and references therein). Moreover, the timing of the release of the executive summary coincided with a US decision on whether to allow landing rights to the Anglo-French Concorde.

In parallel to CIAP, an independent assessment was undertaken by the NAS [31] entitled "Environmental impact of stratospheric flight". The NAS report similarly concluded that large-scale stratospheric emissions of $\mathrm{NO}_{\mathrm{x}}$ might lead to unacceptable reductions in stratospheric $\mathrm{O}_{3}$. Interestingly, the NAS and CIAP reports also pointed to potential depletion of stratospheric $\mathrm{O}_{3}$ by subsonic aircraft.

Shortly after the CIAP programme was initiated, the UK and France organized scientific assessments under the auspices of the "Committee on Meteorological Effects of Stratospheric Aircraft" (COMESA) and "Comite d'Etudes sur les Conséquences des Vols Stratosphériques" (COVOS). The COMESA assessment ran from 1972 to 1975 and issued its final report in 1976, as did COVOS [32,33]. Broadly, the conclusions of the CIAP, NAS, COMESA and COVOS assessments were qualitatively in agreement [34]. The consideration of COMESA over subsonic impacts was not as detailed as those from CIAP and NAS, and COVOS made no mention of these.

COMESA initiated modelling studies along with field and laboratory measurements. In the early 1970s, chemical models of the atmosphere were in their infancy and mostly relied upon 1D models, simply describing the atmosphere in terms of height. Although COMESA discussed at length the uncertainties involved in the modelling, one of the more significant points was that $\mathrm{CH}_{4}$ oxidation chemistry was included in the $1 \mathrm{D}$ chemical 
modelling (in contrast to CIAP). So-called (at the time) "smog chemistry" was an important inclusion in models of the atmosphere. This came about from a realization that tropospheric $\mathrm{O}_{3}$ was not simply a product of stratospheric incursion of air but rather in situ chemical production from the addition of $\mathrm{NO}_{x}$ [35]. This important development resulted in uncertainties over the sign of the $\mathrm{O}_{3}$ change at different levels of $\mathrm{NO}_{\mathrm{x}}$ injection in the 1970s [34].

Although CIAP concluded in 1974, publishing its findings in 1975, stratospheric research continued under two parallel lines in the US. The first was under the US Federal Aviation Administration's (FAA) High Altitude Pollution Program (HAPP), under which a comprehensive comparison of the findings of CIAP NAS and COMESA was undertaken [36]. Secondly, the National Aeronautics and Space Administration (NASA) initiated its Upper Atmosphere Research Program (UARP) in 1976. Whilst UARP was not directed specifically at SST impacts, it contributed towards a better understanding of stratospheric processes and chemistry. In 1991, UARP sponsored reviews of the impacts of aircraft emissions on the stratosphere [37,38], following on the update provided by [39].

The next major initiative in the US was NASA's High-Speed Research Program (HSRP), in the late 1980s. The HSRP was an umbrella research initiative that covered all aspects, including technology, materials, environment, etc., in the development of a new supersonic aircraft. The atmospheric science components had their roots in the FAA HAPP and NASA UARP research programmes. As part of HSRP, the Atmospheric Effects of Stratospheric Aircraft Project (AESA) was initiated in 1988. AESA reported its initial progress in 1992 [40] and the second and third programme reports were given by [41,42] and an interim assessment report by [43]. This 1993 assessment report was independently reviewed by the US National Research Council [44]. In 1995, a second assessment report of AESA was published [45], which was reviewed by the National Research Council [46].

Around the same period, ICAO and the Parties to the Montreal Protocol on Substances that Deplete the Ozone Layer requested the Intergovernmental Panel on Climate Change (IPCC) to provide an assessment of the atmospheric effects of aviation. This was published in 1999 [4], a year after the US announced termination of the HSRP for economic reasons, following Boeing's announcement that it no longer intended to pursue developing an SST, largely on economic and noise grounds. The IPCC report [4] provided a focus for synthesis of many results of various efforts that envisaged a large fleet of supersonic aircraft (500-1000 by 2040) cruising at Mach 2.4 with an emission index for $\mathrm{NO}_{\mathrm{x}}$ of $5 \mathrm{~g} \mathrm{NO} / \mathrm{kg}$ fuel. Perhaps the most significant new result of the IPCC assessment of such a potential SST fleet was from the warming effect of water vapour emitted directly into the dry mid-stratosphere of 50-100 $\mathrm{mW} \mathrm{m}^{-2}$ for the $500 / 1000$ fleet sizes.

Research on the atmospheric impacts of SSTs has been sparse and fragmented over the last two decades, with two notable European programmes: "SCENIC" (Scenario of aircraft emissions and impact studies on chemistry and climate) and "HISAC" (Environmentally friendly high-speed aircraft). More recently, some of the older SST fleet assumptions have been re-examined with up-to-date state-of-the-art climate/chemistry models [10,47], and NASA recently sponsored an analysis of a more up-to-date set of fleet assumptions [11]. Reference [8] also examined the potential effects of a Mach 5 to 8 hypersonic aircraft fleet.

\section{Prospects on Various Concepts}

In recent years, there has been a resurgence in interest in developing a second generation of civil SST aircraft, and a number of commercial projects have been under development and/or discussion. As of November 2021, there are projects under active development from two companies, Boom Technology and Spike Aerospace Inc, both based in the US. The Boom Technology company announced in 2016 the development of a larger civil supersonic product. The current Boom Overture project is for a 60- to 88-passenger supersonic jet capable of flying Mach 2.2. Boom is collaborating with Rolls-Royce with the aim of developing a suitable propulsion system for the supersonic jet and the roll-out of the Overture is planned for 2026 with entry into service in 2029 [48]. 
Spike Aerospace has announced the development of a supersonic business jet, the S-512, for up to 18 passengers that is capable of flying at Mach 1.6 [49]. In 2018, the company stated that it planned for the S-512 to be flying by early 2021, with customer deliveries starting in 2023. However, at the time of writing, no flight tests or application for certification has occurred.

The Aerion Corporation had until very recently also been one of the major players in this field with a supersonic business jet in development since 2008, but this company ceased future work in May 2021 citing insufficient capital to bring its AS2 programme to market [50].

NASA research since 2006 has focused on reducing the sonic boom to allow supersonic flight over land. NASA plans to fly a low-boom demonstrator, the X-59 QueSST, in the early 2020s. NASA has also developed a Supersonic Technology Concept Aeroplane (STCA) business jet for the purpose of studying the environmental impacts of a new supersonic business jet [51]. The NASA STCA is capable of carrying eight passengers at Mach 1.4 over a range of $4000 \mathrm{NM}$. It has a maximum take-off mass of 55,000 kg and three engines. It has been developed using publicly available information, including an engine derived from a contemporary, "off-the-shelf" subsonic turbofan (CFM-56 derivative).

The Russian Federation TsAGI also exhibited at the 2017 MAKS Air Show in Moscow a scale model of its Supersonic Business Jet/Commercial Jet that should produce a low sonic boom permitting supersonic flight over land, optimised for $2100 \mathrm{~km} / \mathrm{h}$ (1300 mph) cruise and 7400-8600 km (4600-5300 $\mathrm{mi}$ ) range [52]. The TsAGI scientific research programme aims to optimise for both Mach 0.8-0.9 transonic and Mach 1.5-2.0 supersonic speeds, but little more is in the public domain about this project.

The European Commission funded two research projects on SST and environmental impacts during the 2000s: (1) SCENIC, which ran from 2002 to 2005, and (2) HISAC, which ran from 2005 to 2009 . The SCENIC project considered scenarios based on a relatively large supersonic aircraft to be operated at Mach 2, with 250 passengers, a maximum range of $5500 \mathrm{NM}$ and a cruise altitude from 17 to $20 \mathrm{~km}$. The HISAC project considered a smaller supersonic business-jet-type aeroplane with a range of configurations (2, 3 and 4 engines, maximum take-off mass of between 30 to 60 tonnes and ranges from regional to long-range flights). The underlying assumptions of the SCENIC and HISAC projects are described in more detail in the following section. There are two EC-funded projects (both started in January 2021) on supersonic aviation and environmental impacts: SENECA and MOREandLESS (MDO and REgulations for Low-boom and Environmentally Sustainable Supersonic aviation). SENECA focusses on business-jet-type supersonic aeroplanes with Mach Number 1.4 and 1.6 and a larger civil aeroplane with Mach Numbers 1.8 and 2.2, and MOREandLESS has a focus across the full range of supersonic speeds. Both projects will consider the noise, emissions and environmental impacts of SST aviation.

\section{Emission Inventories and Scenarios}

Emissions data are required in climate impact assessments. This could be defined as global emissions per year that can be used in simple climate models or detailed global 3D emissions that are generally a pre-requisite in chemical transport models (CTMs) or general circulation models (GCMs). However, detailed descriptions of supersonic emissions inventories have been limited since the publications referenced in the IPCC Special Report on Aviation and the Global Atmosphere [4]. Since then, despite numerous studies conducted on SST and its impacts on the atmosphere, details on inventories are generally provided as sub-sections in impact publications, alongside scenario assumptions. One important design variable here is assumptions on emission indices (EI) for key species comprising nitrogen oxides and soot emissions, which are dependent on engine performance, and water vapour, which is dependent on fuel composition.

The construction of supersonic emissions inventory is generally more complex than their subsonic counterparts. There is a long history of established subsonic aircraft data and methodologies in terms of fleet composition, demand forecasting and flight profiles that 
are independent of routes. There have only been two commercial supersonic airliners that have been in service: the Concorde that served mainly limited routes between Europe and the east coast of the US and the Tupolev-144 that briefly served the former Soviet Union. Therefore, there are limited data in terms of future fleet composition, demand, vehicle and engine performance and flight profiles and trajectories. The inventory generated will have to make assumptions such as:

- The number of supersonic vehicles available and the market that they serve (passenger mainliner and/or business jet), including the airports that they will operate from.

- Whether the supersonic demand is in addition to existing subsonic demand or replacing existing subsonic operations (entire operation or part of the operation such as business class only in passenger mainliner) and the rate of supersonic fleet growth and subsonic fleet replacements, if any, and the number of vehicles available for this.

- Whether the supersonic vehicle is permitted to fly at supersonic speeds over land and consequently if the flight will traverse the coastline(s) to save flight time or if the flight will require a fuel stop.

- Emissions indices for species such as $\mathrm{NO}_{\mathrm{x}}$ that are dependent on engine performance and atmospheric ambient conditions.

- Whether the emissions generated are uni- or bi-directional (i.e., the outbound flight characteristics are assumed to be the same as the inbound).

There have been studies that focused only on the emissions without undergoing any climate modelling, such as [53] on $\mathrm{CO}_{2}$ emissions quantification and those conducted under the ASCENT project [54]. A summary of the studies that investigated global atmospheric effects is given in Table 1.

Table 1. Overview of supersonic projects/scenarios.

\begin{tabular}{|c|c|c|c|c|}
\hline & IPCC $[4,55]$ & SCENIC [9] & HISAC [12] & NASA [11] \\
\hline Reference aircraft (type) & Boeing (Airliner) & Airbus (Airliner) & Dassault, Alenia, Sukhoi (BizJet) & Concorde (Airliner) \\
\hline Mean cruise altitude (km) & $17-20$ & $16-19$ & $15-16$ & 16.7 \\
\hline Number of aircraft & $500 / 1000$ & 501 & 250 & $440-470$ \\
\hline Passengers & 309 & 250 & 8 & 60 \\
\hline Speed (Mach) & 2.4 & 2.0 & $1.6-1.8$ & 1.6 \\
\hline Maximum range (NM) & 5000 & 5400 & 4000 & 4500 \\
\hline Fuel consumption ( $\mathrm{Tg} /$ year) & $70 / 140$ & 60 & 0.4 & 16.8 \\
\hline $\mathrm{EI}\left(\mathrm{NO}_{\mathrm{x}}\right)\left(\mathrm{g}\left(\mathrm{NO}_{2}\right) / \mathrm{kg}(\right.$ fuel $\left.)\right)$ & 5 & 4.6 & $10.5-12$ & 8.8 \\
\hline $\mathrm{EI}\left(\mathrm{H}_{2} \mathrm{O}\right)\left(\mathrm{kg}\left(\mathrm{H}_{2} \mathrm{O}\right) / \mathrm{kg}\right.$ (fuel $\left.)\right)$ & 1.23 & 1.25 & $\mathrm{n} / \mathrm{a}$ & 1.26 \\
\hline Time of full fleet & 2050 & 2050 & 2050 & 2035 \\
\hline
\end{tabular}

Distance travelled, which is an important parameter in the modelling of contrails and contrail cirrus, has not been included in Table 1. This is due to the inconsistency between how distances are reported within the studies and/or lack of information. For example, the distances reported by the SCENIC project are for the subsonic and mixed fleet scenarios. The supersonic fleet distance cannot be derived from these since the mixed fleet scenario includes an assumption of subsonic fleet replacement. Distance travelled does not directly scale with the number of aircraft and/or the seat kilometres. In the case of supersonic vehicles, where non-great circle distance routes are likely to be flown to avoid sonic boom over land, the determination of this parameter becomes even more complex and should not be omitted.

For the SCENIC project, the inventories generated included a mixed fleet of subsonic and supersonic scenarios for the years 2025 and 2050, with 211 and 501 supersonic aircraft, respectively (Table 1). Additionally, there were five "perturbation" scenarios that were constructed to investigate the sensitivity to the doubling of the market size from a maximum of $30 \%$ assumed for the normal case, engine technology resulting in changes in $\mathrm{EI}\left(\mathrm{NO}_{\mathrm{x}}\right)$, cruise speed, maximum range and flight altitudes. The main scenarios were constructed with market forecasts for air traffic demand and the assumption that sonic boom is not allowed over land, with modification to the trajectories that increased the distance travelled on some routes $[9,56]$. 
There is limited published information on the HISAC inventory. HISAC only considered a supersonic fleet, in idealized scenarios, unlike SCENIC, where a mixed fleet was considered alongside potential traffic demand. These scenarios accounted for three different fleets consisting of different supersonic aircraft (Table 1).

A recent NASA study generated detailed inventories that included several scenarios [11]. These accounted for variation in the vehicle specifications (range/speed) from literature, dating from 2004 (updated Concorde design) to newer ones from 2020 (NASA, Boom Aerion). The fleet penetration for the scenarios is based on market demand and includes provisions for overland flights with and without regulatory noise constraints.

There have also been older studies by NASA (outlined in [4]) and other newer studies within the US project ASCENT [54] and by the ICCT [53,57]; however, they are not described in this review paper as the main focus of these studies are on noise and/or global $\mathrm{CO}_{2}$ and $\mathrm{NO}_{\mathrm{x}}$ LTO emissions.

\section{Atmospheric Effects of Supersonic Aviation}

\subsection{Effect of Nitrogen Oxides-Homogeneous Chemistry}

Nitrogen oxide emissions from conventional and supersonic aviation released in the atmosphere act as a reactive species and cause changing concentrations of radiatively active species, such as ozone and methane, through photochemical processes. Hence, these emissions influence the radiative balance and eventually contribute to climate change.

Increased $\mathrm{NO}_{\mathrm{x}}$ concentrations caused by aircraft emissions influence the ozone concentration through different pathways. In the stratosphere, $\mathrm{NO}_{\mathbf{x}}$ mainly acts as a catalyst in the destruction of ozone through the following reaction chain [4]:

$$
\begin{gathered}
\mathrm{O}_{3}+\text { sunlight } \rightarrow \mathrm{O}+\mathrm{O}_{2} \\
\mathrm{O}+\mathrm{NO}_{2} \rightarrow \mathrm{NO}+\mathrm{O}_{2} \\
\mathrm{NO}+\mathrm{O}_{3} \rightarrow \mathrm{NO}_{2}+\mathrm{O}_{2}
\end{gathered}
$$

This reaction is particularly efficient for high concentrations of ozone.

Through both vertical mixing and direct emissions, supersonic aviation also impacts the $\mathrm{NO}_{\mathrm{x}}$ concentrations in the upper troposphere/lower stratosphere (UT/LS) region, where ozone is produced in the presence of $\mathrm{NO}_{\mathrm{x}}, \mathrm{HO}_{2}$ and sunlight. The dependence of the ozone production on the $\mathrm{NO}_{x}$ concentration is highly non-linear [58] in general, with a peak at a background concentration of $5.00 \times 10^{-10} \mathrm{~mol} / \mathrm{mol}$ and additional $\mathrm{NO}_{\mathrm{x}}$ in the atmosphere at very high background levels even leading to a destruction of ozone. However, at the typical lower background concentrations of 50 to $2.00 \times 10^{-10} \mathrm{~mol} / \mathrm{mol}$ found in the UT/LS region, $\mathrm{NO}_{x}$ emissions from aviation lead to ozone production in an almost linear fashion.

In an earlier study investigating the effects of emissions from a supersonic fleet, it was shown that the ozone concentration is dynamically and chemically controlled, with an increasing importance of the dynamics for decreasing altitude [9]. It was also shown that in the stratosphere, $\mathrm{NO}_{x}$ emissions from supersonic aircraft lead to a decrease in ozone concentration, whereas in the UT/LS region, the resulting effects on ozone vary between models: models may predict either a slight increase or a decrease in the concentration depending on the efficiency of vertical mixing in the particular model and the cruise altitudes assumed. Specifically, Reference [9] found an increase in the UT/LS region for two models (E39/C and ULAQ-CCM) and almost no change for two other models (SLIMCAT and OsloCTM2). A recent study using the GEOS-Chem model also found only a small increase in ozone in the lower stratosphere, compared with a strong decrease at higher altitudes [11]. Similarly, the degree of hemispheric asymmetry between different models varies $[9,11]$. The magnitude and distribution of the ozone perturbation caused by emissions of supersonic aircraft also depend strongly on the emission altitude [47]. For high-altitude emissions, stratospheric ozone depletion dominates, whereas for loweraltitude emissions, the increase in ozone in the UT/LS dominates. One study found an 
inflection point at about $17 \mathrm{~km}$, where the total column ozone change switches signs [47]. Furthermore, ozone concentrations undergo a seasonal cycle, leading to a larger total ozone column in spring and a smaller total ozone column in fall and winter at high northern latitudes $[47,59]$.

Ozone concentration changes are not only caused by $\mathrm{NO}_{\mathrm{x}}$ emissions but also by emissions of water vapour and sulphate aerosols (see Section 5.3). Water vapour acts as a catalyst in the destruction of ozone through various reactive cycles [60] in a similar fashion to $\mathrm{NO}_{\mathrm{x}}$. The ozone loss through water vapour emissions dominates over the loss through $\mathrm{NO}_{\mathrm{x}}$ emissions at altitudes higher than about $40 \mathrm{~km} \mathrm{[10].} \mathrm{In} \mathrm{terms} \mathrm{of} \mathrm{the}$ relative magnitude of the ozone destruction through $\mathrm{NO}_{\mathrm{x}}$ and $\mathrm{H}_{2} \mathrm{O}$, two studies found that the $\mathrm{H}_{2} \mathrm{O}$ effect is about five times weaker [11,59], whereas one study found roughly similar magnitudes for $\mathrm{EI}\left(\mathrm{NO}_{\mathrm{x}}\right)=5 \mathrm{~g} / \mathrm{kg}$ fuel and an accordingly greater importance of $\mathrm{NO}_{\mathrm{x}}$ for larger EI $\left(\mathrm{NO}_{\mathrm{x}}\right)$ values [10]. Because there are multiple pathways of ozone concentration changes, RF (see Section 6) associated with ozone changes should not be solely attributed to $\mathrm{NO}_{\mathrm{x}}$ emissions. Most studies do not attempt to distinguish between the different contributions when presenting results for ozone concentration changes and the resulting RF. Ozone RF is generally a function of the strength and the pattern of the perturbation as well as the background atmospheric composition [9]. The RF from per-unit changes in ozone in the middle stratosphere is much smaller than in the UT/LS region and can even be negative [61]. Reference [9] found ozone RF ranging from $-8.6 \mathrm{~mW} / \mathrm{m}^{2}$ to $4.7 \mathrm{~mW} / \mathrm{m}^{2}$ for four different models for the SCENIC replacement scenario (Table 1). The mean RF change of the four models is $-2.8 \mathrm{~mW} / \mathrm{m}^{2}$ for this scenario. Earlier model results predicted an RF of $-10(-40,10) \mathrm{mW} / \mathrm{m}^{2}$ from an ozone perturbation from SST $\mathrm{NO}_{x}$ and $\mathrm{H}_{2} \mathrm{O}$ emissions in the NASA/IPCC inventory [4]. A recent study, Reference [10], reanalysed this scenario with the CESM/WACCM4 model. Their model predicts a strong increase of ozone in the UT/LS region, increasing the concentration by over $1 \%$ with respect to the background concentration in the northern hemisphere. In terms of RF, this increased concentration in the UT/LS dominates over ozone depletion in the upper stratosphere. They found an RF of $20.4 \mathrm{~mW} / \mathrm{m}^{2}$ for an $\mathrm{EI}\left(\mathrm{NO}_{\mathrm{x}}\right)$ of $15 \mathrm{~g} / \mathrm{kg}$ fuel, which they can exclusively attribute to $\mathrm{NO}_{x}$ emissions. Finally, Reference [11], despite encountering a predominantly negative ozone perturbation with a pattern very similar to that of the SLIMCAT model [9], found an ozone $\mathrm{RF}$ of $2.9 \mathrm{~mW} / \mathrm{m}^{2}$, noting, however, that only $35 \%$ of the ozone originated from SST NO $\mathrm{N}_{x}$ emissions. This nevertheless positive RF may be a result of their inclusion of ozone perturbations above $10 \mathrm{hPa}$ into the RF computation, a slightly larger positive perturbation in the troposphere, the different radiative code used or the different background atmospheric composition.

Earlier studies also showed that SST emissions of $\mathrm{NO}_{\mathrm{x}}$ also impact the methane lifetime in the atmosphere through two processes: Firstly, ozone changes in the troposphere lead to an enhanced availability of $\mathrm{OH}$, as the reaction of $\mathrm{OH}$ with $\mathrm{CH}_{4}$ is the principal removal term for $\mathrm{CH}_{4}$ in the atmosphere. Secondly, more UV radiation can penetrate into the troposphere due to a reduced total ozone column, increasing chemical activity [9]. However, compared with other effects, the limited evidence suggests that the climate impact through methane is of relatively minor importance in the case of supersonics.

\subsection{Aerosols—Direct Effect}

Both subsonic and supersonic aviation that uses conventional fossil fuel emits two kinds of climate-relevant aerosols: black carbon (BC) or "soot", which is directly emitted, and sulphate aerosols $\left(\mathrm{H}_{2} \mathrm{SO}_{4} / \mathrm{SO}_{4}{ }^{2-}\right)$, which are predominantly formed over the oxidation of $\mathrm{SO}_{2}$ into $\mathrm{SO}_{3}$ and the subsequent reaction with $\mathrm{H}_{2} \mathrm{O}$ to form $\mathrm{H}_{2} \mathrm{SO}_{4}$. Due to the small size of aerosol particles, the long-wave RF is negligible for both types.

In the short-wave regime, the dominant effect of sulphate aerosols is scattering, leading to a negative RF, whereas for $\mathrm{BC}$, absorption dominates, leading to a positive RF. One modelling study with a course resolution including 144 horizontal grid cells on 26 vertical levels found an RF of $4.6 \mathrm{~mW} / \mathrm{m}^{2}$ and $-11.4 \mathrm{~mW} / \mathrm{m}^{2}$ for $\mathrm{BC}$ and sulphate aerosols through 
supersonic aviation emissions, respectively, computed using the SCENIC replacement scenario [62] (Table 1). This study also investigated modified SCENIC scenarios which gave RFs ranging from 0.4 to $11.0 \mathrm{~mW} / \mathrm{m}^{2}$ for $\mathrm{BC}$ and -3.9 to $-23.3 \mathrm{~mW} / \mathrm{m}^{2}$ for sulphate aerosols. The least impactful scenario among these would be a scenario with a reduced flight altitude and a resulting shorter residence time of the aerosol particles. A recent NASA study also computed the RF of aerosols and found an RF of $-6.6 \mathrm{~mW} / \mathrm{m}^{2}$ for a fleet of 440 to 470 supersonic aircraft travelling at Mach 1.6 and a fuel sulphur content of $600 \mathrm{ppm}$, including negative RF for both BC and sulphate aerosols [11], suggesting that there is uncertainty over the sign of the $\mathrm{BC}$ forcing.

\subsection{Aerosols—Indirect Effect through Heterogeneous Chemistry}

Apart from the direct radiative impact of sulphate and $\mathrm{BC}$ aerosols described in the previous section, aerosols also alter the radiative transfer in the atmosphere indirectly through various effects. Firstly, aerosol particles serve as surfaces, on which heterogeneous chemical reactions can occur. With an increased number of sulphuric acid particles, the conversion rate of $\mathrm{NO}_{\mathrm{x}}$ into $\mathrm{HNO}_{3}$ increases, resulting in a depletion of $\mathrm{NO}_{\mathrm{x}}$ and a subsequent increase in $\mathrm{O}_{3}$ in the upper stratosphere (above approximately $17 \mathrm{~km}$ ). Reference [59] found that the ozone production in the Northern mid-latitude stratosphere caused by total aerosol emissions, including subsonics, in the SCENIC scenario for 2050 (Table 1), may be roughly twice as large as the ozone production caused by background aerosols, illustrating the importance of aircraft-emitted aerosols for heterogeneous processes in the stratosphere. However, the increased aerosol surface area density caused by sulphur emissions also enhances the halogen chemistry, leading to a destruction of ozone in the extremely cold conditions of the polar lower stratosphere [63]. Secondly, aerosols in the stratosphere scatter UV radiation, resulting in a lower photodissociation of $\mathrm{O}_{2}$ and $\mathrm{NO}_{2}$ in the UT/LS which can cause a lower $\mathrm{O}_{3}$ production [64]. Thirdly, the change of stratospheric heating rates through the direct and other indirect effects of increased aerosol concentrations causes changes in the stratospheric circulation [65].

Previous studies have often omitted the indirect aerosol effects of supersonic aviation emissions, which are known to represent a large uncertainty [4]. One study found that the indirect aerosol RF is highly variable between models, mainly because of the different dynamics influencing the removal efficiency of $\mathrm{NO}_{x}$ from the emission region [62]. However, as their model had to rely on very coarse spatial resolution and strongly parameterised aerosol dynamics processes, we do not include their results in this study. Another recent study found that the indirect effects of sulphate aerosols contribute more than half of the ozone loss in the stratosphere from supersonic aircraft emissions [11], but it did not distinguish between the contributions of different indirect effects. The effect of additional sulphate aerosols in the stratosphere is also studied in the context of geoengineering, where studies find a resulting net decrease in ozone [64,65]. However, due to the different spatial patterns of the aerosol perturbation, these scenarios are not directly comparable to the case of supersonic aviation.

In total, combining direct and indirect effects, particle-related RF may be of similar magnitude but of opposing sign compared with the RF associated with water vapour [9]. However, a large source of uncertainty in these results is the difficulty in accurately predicting aerosol emissions of a supersonic fleet, which strongly depends on the engine technology and the fuel type used (e.g., fossil-based or bio/synthetic-based fuels which have inherently lower concentrations of sulphur and aromatic compounds, the precursors of the aerosol types).

\subsection{Stratospheric Water Vapour Effects}

Water vapour $\left(\mathrm{H}_{2} \mathrm{O}\right)$ is a strong greenhouse gas associated with a warming effect at the surface. However, while aviation injects $\mathrm{H}_{2} \mathrm{O}$ into both the troposphere and the lower stratosphere, it is a small perturbation to the natural hydrological cycle. Consequently, the $\mathrm{RF}$ of a unit of water vapour is largest in the stratosphere, where the natural background 
humidity is low such that any additional water vapour can have a larger RF per unit emission than subsonic aviation [66]. Water vapour emitted in the stratosphere may be the main consideration for the total supersonic air traffic's radiative impact, with the residence time of aviation's water vapour emissions in the atmosphere being sensitive to the height above the tropopause [67], with emissions at higher altitudes persisting longer in the stratosphere, leading to greater accumulation of aviation water vapour and greater RF. Increases in stratospheric water vapour cool the stratosphere while warming the troposphere.

Several studies have estimated the radiative effects of water vapour from a hypothetical supersonic fleet, Reference [68] found a stratospherically adjusted RF of 10 and $44 \mathrm{~mW} \mathrm{~m}^{-2}$ from 500 and 1000 aircraft, respectively, while [9] estimated $16-36 \mathrm{~mW} \mathrm{~m}^{-2}$ linked to water vapour from $60 \mathrm{Tg}$ of fuel used by aircraft cruising at 16-20 km, with a mean value amongst models of $23 \mathrm{~mW} \mathrm{~m}^{-2}$, similar to [11], who estimated a value of $11 \mathrm{~mW} \mathrm{~m}^{-2}$ assuming a cruise altitude of $19 \mathrm{~km}$ and $15 \mathrm{Tg}$ of fuel burn. A compilation reported values between 15 and $35 \mathrm{~mW} \mathrm{~m}^{-2}$ in 2050 with a mean value of $23 \mathrm{~mW} \mathrm{~m}^{-2}$ [5].

A recent update on previous studies [10] on supersonic aircraft emissions estimated the stratospherically adjusted $\mathrm{RF}$ from $\mathrm{H}_{2} \mathrm{O}$ as approximately $42 \mathrm{~mW} \mathrm{~m}^{-2}$ for a fleet size of 500 and $74 \mathrm{~mW} \mathrm{~m}^{-2}$ for a fleet of 1000 aircraft, consistent with the $30-300 \mathrm{~mW} \mathrm{~m}^{-2}$ range derived in the earlier 1999 NASA and IPCC assessments [4,69]. Despite the small size of the assumed fleets, these values are an order of magnitude larger than the best estimate for the current subsonic fleet, reported by [7], who compiled the radiative effect of $\mathrm{H}_{2} \mathrm{O}$ from nine studies ranging from 0.4 [70] to $1.5 \mathrm{~mW} \mathrm{~m}^{-2}$ [71,72] to $3.0 \mathrm{~mW} \mathrm{~m}^{-2}$ [4], attributing the differences between the models from the underlying atmospheric transport and meteorology schemes used. After normalizing and scaling the sensitivity of these studies, they reported an effective RF (ERF) best estimate of $2.0 \mathrm{~mW} \mathrm{~m}^{-2}\left(0.8,3.2 \mathrm{~mW} \mathrm{~m}^{-2}\right)$ for 2018, which, in turn, is modest compared to that from the corresponding contrail cirrus estimate, $57(17,98) \mathrm{mW} \mathrm{m}^{-2}$, from the same authors.

To put these results into context, the current aviation fleet injects a large fraction of its water vapour emissions into the lower stratosphere [70,73], but the calculation of the radiative effect from stratospheric $\mathrm{H}_{2} \mathrm{O}$ emissions is complicated by its sensitivity to vertical and horizontal distribution, which both affect its location relative to the tropopause. The latitudinal and seasonal variability of the tropopause and the influence of the chosen tropopause definition on the tropopause altitude used in a given study add further uncertainty to the radiative calculations. Moreover, the uncertainties amongst radiation schemes were reported by [9] as a factor of two for the same water vapour perturbation and background fields [9], while [74] also found differences of about a factor of two for water vapour but concluded that cancellations of differences may imply larger uncertainties while reporting smaller differences amongst models linked to contrail calculations compared to water vapour. This could be expected from the fact that all the models in that intercomparison study prescribed the same contrail optical properties, while for water vapour, each model used its own radiative parameterisation. These results suggest that the radiative transfer uncertainties linked to water vapour aviation emissions are probably not dissimilar to those of other forcers but that larger uncertainties may be expected with respect to the dependence of residence times on altitude and the definition of the tropopause, as the processes that control their distribution and even the local temperature are poorly represented in current global climate models, together with the complexities involved in incorporating chemical feedbacks that affect water vapour stratospheric concentrations.

\subsection{Formation of Contrails and Contrail Cirrus}

Condensation trails, also referred to as contrail or cirrus homogenitus in the WMO's international cloud atlas, when persistence is $<10 \mathrm{~min}$, are anthropogenic high-level ice clouds. Their occurrence is driven by the combination of the engine/airframe performance characteristics, the chemical composition of the jet engine fuel and the ambient meteorological conditions, while their persistence and evolution into cirrus-like clouds 
will depend mainly on ambient conditions that should be sufficiently cold and humid. Contrail formation has mostly been studied for subsonic aviation $[7,75,76]$ as most air traffic occurs at subsonic speeds and all commercial civil supersonic aircraft stopped since the retirement of Concorde in 2003. Only a few studies have quantified the global climate effect of contrails linked to supersonic aviation. Reference [56] produced a comprehensive overview of the climate effect contribution from supersonic aircraft based on multiyear global climate model simulations using different air traffic inventories for subsonic and mixed fleets in which a part of the subsonic aircrafts is replaced by a fleet of supersonic aircraft over the 2025-2050 period. The share of the supersonic fleet is modulated according to the SCENIC project scenarios described in [9]. For 2050, the [56] study showed that when part of the subsonic fleet is replaced by a supersonic aircraft (e.g., 250 passengers, Mach 2 with a range of $5500 \mathrm{NM}$ and a cruise altitude of 55-65 kft), the fuel consumption increases over the tropics $(+7.4 \%)$, the North Atlantic $(+10.8 \%)$ and the North Pacific $(+8.1 \%)$. Moreover, the fuel consumption increase is concomitant with an increase in total contrail cover over tropical regions with a maximum increase of $0.8 \%$ over Southeast Asia in 2050. The results also show an increase in the total contrail cover over central Europe and the USA caused by supersonic aircraft flying in subsonic mode over land to avoid a sonic boom. In contrast with the increase in contrail cover modelled over the tropical regions, a global decrease is simulated over the northern extratropics, especially over the North Atlantic, because the drier ambient conditions at supersonic flight levels are less favourable for contrail formation than those at subsonic flight levels. A small increase was noted in the Northern extratropical stratosphere (above $100 \mathrm{hPa}$ ) only during winter where cold enough ambient temperature conditions, favourable to contrail occurrence, are met. Globally, when the supersonic fleet is deployed, the RF of contrails is reduced by $0.1 \mathrm{~mW} \mathrm{~m}^{-2}$ in 2025 and $0.5 \mathrm{~mW} \mathrm{~m}^{-2}(-2 \%)$ in 2050 based on the assumption of constant revenue passenger kilometre (RPK). According to this study, the reduced global contrail coverage and optically thinner contrail linked with drier conditions observed in the lower stratosphere than in the upper troposphere are the main reasons for the calculated RF reduction. Note that a reduced Mach number applied to the supersonic fleet leads to an increase in the RF of $0.1 \mathrm{~mW} \mathrm{~m}^{-2}$.

Contrail formation and persistence are difficult to predict due to the complexity of the mechanism involved in their formation. In the case of supersonic aviation, only a few studies are available in the literature, and some interrogations remain on the sensitivity of the parameters that control the contrail ice crystal distributions evolution during the contrail lifetime. However, based on the current knowledge, a few processes can be seen as crucial and deserve specific attention in order to determine the contrail formation and persistence from a supersonic fleet.

The first key parameter is the soot emission indices that are directly linked to the engine and fuel characteristics as shown by [77]. Although current ongoing projects such as SENECA plan to use a classical current type of fuel such as Jet-A1, the fuel choice and the combustion technology will be key in the determination of the soot emission index that will affect the ice crystal distribution characterizing the contrails and their climate effect.

The second parameter corresponds to the position of the aircraft during a given mission (e.g., latitude, longitude, altitude) that is directly dependant on the mission profile and the city pairs. For example, deeper persistent contrail conditions were identified at supersonic flight level by [11] and could lead to longer contrail lifetime and therefore greater climate effect.

More recently, a report published by NASA [11] reported the likelihood of areas where contrails could form and persist introducing the PCC criterion based on sonde probe meteorological observations as well as engine and fuel characteristics. For supersonic aircraft, they found that cruise altitude is a key factor that determines the probability for an aircraft to encounter PCC and therefore to form a persistent contrail. Indeed, the results show that the likelihood of PCC areas is a factor 2 greater at $17 \mathrm{~km}$ than at $10.5 \mathrm{~km}$ (subsonic cruise altitude) in the tropics but a factor 105 smaller between the same altitudes near the poles. According to their results, supersonic flights in the tropics (low-latitude band) would 
have a $25 \%$ greater likelihood to form a persistent contrail than subsonic flights, whereas in the Artic (high-latitude band), the logic is reverse as supersonic flights would have a $77 \%$ smaller likelihood to form persistent contrails compared with subsonic flights. The study also underlined that the persistence of contrails could be greater for supersonic traffic due to their formation location taking place in a more stable thermo-dynamical environment leading to a higher horizontal extension (e.g., cruise level at 8-15 km) of supersonic-induced contrails compared to subsonic-induced contrails (e.g., cruise level at $5-10 \mathrm{~km}$ ). Moreover, the drier stratospheric ambient condition also produces optically thinner contrails with a lower ice mass content compared to tropospheric contrails that could affect the associated ERF. Overall, they concluded that a displacement of subsonic travel by supersonic flights is likely to result in a net decrease in contrail impacts. Such a conclusion is highly dependent on the assumptions of the particular scenario.

\subsection{Carbon Dioxide Effects}

The climate effects associated with supersonic $\mathrm{CO}_{2}$ emissions are not as sensitive to cruise altitudes as those of $\mathrm{O}_{3}$ and $\mathrm{H}_{2} \mathrm{O}$ emissions because $\mathrm{CO}_{2}$ is homogeneously mixed in the atmosphere. In general, supersonic aircraft burn more fuel per RPK than subsonic aircraft, increasing the $\mathrm{CO}_{2} \mathrm{RF}[4,9,10]$. The assessment of the climate effect of $\mathrm{CO}_{2}$ emissions is difficult as it requires the consideration of timescale, e.g., if the supersonic fleet is predicted to mature in 2050, the evaluation of the $\mathrm{CO}_{2}$ effects has to extend much beyond 2050 so the cumulative response can be fully observed.

\section{A Synthesis of Prior Studies' Results}

The environmental impact of the supersonic aircraft fleet is of interest mainly due to concerns related to both its effects on stratospheric $\mathrm{O}_{3}$ and climate change. The emissions from the fleet of aircraft depend on the fleet size, speed, cruise altitude, fuel use at cruise and emission indices. Supersonic aircraft burning conventional aviation fuel emit $\mathrm{NO}_{x}$, water vapour and aerosols directly into the stratosphere. Several studies identified the stratospheric $\mathrm{H}_{2} \mathrm{O}$ emissions as a significant factor in potential climate effect from SST $[4,9,10]$. The climate effect of $\mathrm{H}_{2} \mathrm{O}$ is the most important climate component concerning supersonic aircraft, and its importance increases with increasing cruise altitudes [47] (Figure 1).

Additionally, emissions of $\mathrm{NO}_{\mathrm{x}}$, water vapour and aerosols lead to chemical reactions that cause changes in stratospheric $\mathrm{O}_{3}$. The effect on stratospheric $\mathrm{O}_{3}$ depends on cruise altitudes where early studies indicate stronger negative $\mathrm{RF}$ for $\mathrm{O}_{3}$ at higher cruise altitudes [4,9]. A more recent study [11] reported behaviour different than earlier studies, and their $\mathrm{O}_{3} \mathrm{RF}$ increased with height. The reason for it might be the inclusion of sulphur emissions into the $\mathrm{O}_{3}$ effect or the incorporation of $\mathrm{O}_{3}$ perturbations above the $10 \mathrm{hPa}$ into their RF calculations (see Section 5). In a recent sensitivity study, it was shown that it is the emissions above $17 \mathrm{~km}$ where the effect of the $\mathrm{NO}_{\mathrm{x}}$ catalytic cycle becomes dominant and it leads to $\mathrm{O}_{3}$ depletion [47]. The other important pattern that is observed by various studies is that the $\mathrm{O}_{3}$ depletion in the lower stratosphere $(17-20 \mathrm{~km})$ is highly dependent on $\mathrm{EI}\left(\mathrm{NO}_{\mathrm{x}}\right)$ values and the destruction of ozone is larger when the emission index for $\mathrm{NO}_{\mathrm{x}}$ increases $[4,10,78]$. Overall, the dependence of $\mathrm{O}_{3} \mathrm{RF}$ on cruise altitude is more complex than in the case of $\mathrm{H}_{2} \mathrm{O}$.

The climate impact from potential supersonic aircraft emissions was studied by previous projects and is summarised in Table 2. These projects utilised a series of global atmosphere-chemistry models and a climate response model (AirClim) to estimate the climate effects [79]. These results present very disparate estimates mainly due to different assumptions regarding the potential supersonic fleet that makes it difficult to compare. However, there is one feature in common: uncertainties associated with those numbers that are significant. Recently, Reference [10] reran the supersonic scenarios explored by the 1999 aviation assessment [4], and they found the effects on stratospheric $\mathrm{O}_{3}$ to be similar to many models in the prior assessments (especially 2D models), although with a stronger $\mathrm{O}_{3}$ production efficiency of $\mathrm{NO}_{x}$ emissions. They confirmed the importance of 
stratospheric $\mathrm{H}_{2} \mathrm{O}$ emissions. In addition, despite the methodological differences between various supersonic projects/studies generally, the prevalent pattern emerges where with the increasing cruise altitudes, $\mathrm{H}_{2} \mathrm{O}$ RF increases are observed (Figure 1).

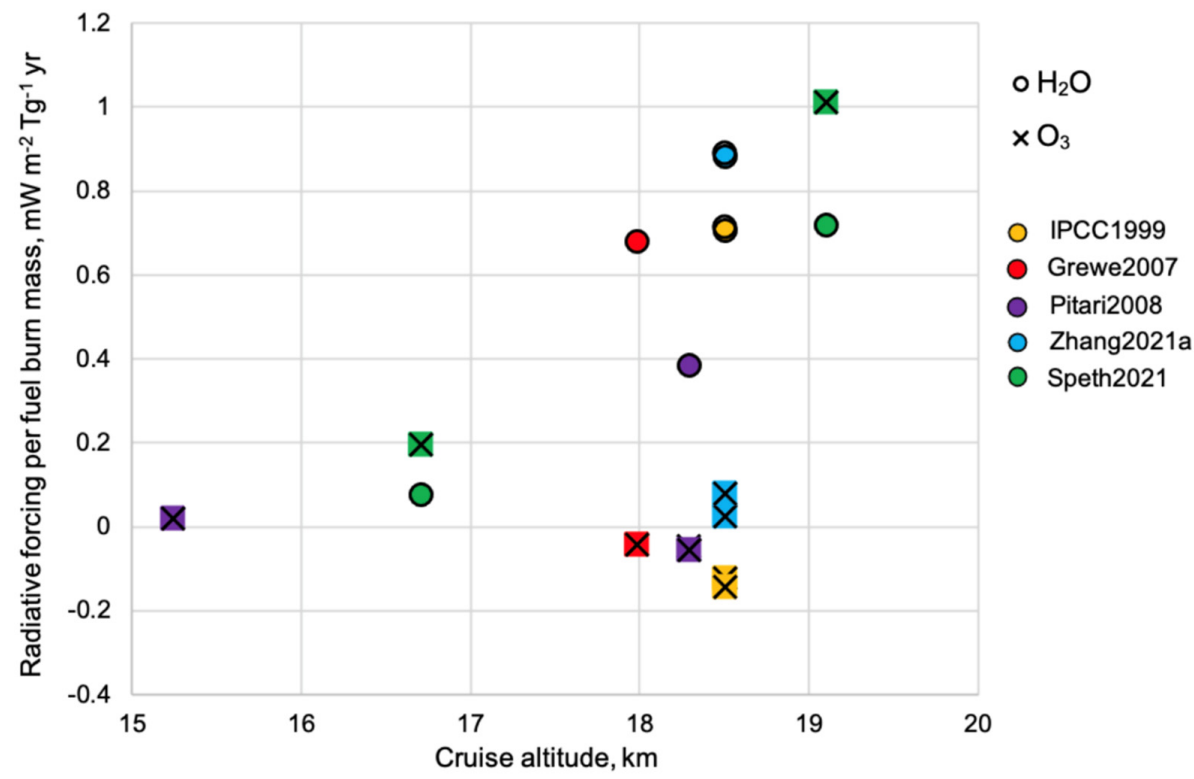

Figure 1. The global changes in RF per fuel burn mass $\left(\mathrm{mW} \mathrm{m}^{-2} \mathrm{Tg}^{-1} \mathrm{yr}\right)$ versus cruise altitudes for the changes in $\mathrm{H}_{2} \mathrm{O}$ and $\mathrm{O}_{3}$ as reported by various studies. Discrepancies in the $\mathrm{O}_{3} \mathrm{RF}$ per burnt fuel can be caused by three effects: the inclusion or omission of ozone changes through aerosol emissions in different models; a different assumed emission index of $\mathrm{NO}_{\mathrm{x}}$; and different radiative transfer computations.

Table 2. Overview on supersonic studies and their estimates of climate effects.

\begin{tabular}{|c|c|c|c|c|c|c|}
\hline & $\left.\operatorname{IPCC}_{4}\right]^{1}$ & SCENIC $[9]^{2}$ & SCENIC [62] & HISAC $[12]^{3}$ & Zhang et al., $2021[10]^{4}$ & NASA $[11]^{5}$ \\
\hline \multicolumn{7}{|c|}{ Fleet assumptions } \\
\hline Mean cruise altitude $(\mathrm{km})$ & $17-20$ & $16-19$ & $16-19$ & $15-16$ & $17-20$ & 16.7 \\
\hline $\begin{array}{c}\mathrm{H}_{2} \mathrm{O} \text { emissions } \\
\left(\mathrm{Tg}\left(\mathrm{H}_{2} \mathrm{O}\right) / \mathrm{yr}\right)\end{array}$ & $86.1 / 172.2$ & 75 & 75 & $0.5^{* * *}$ & $58.1 / 103.9^{* * * *}$ & 21.2 \\
\hline $\begin{array}{l}\mathrm{NO}_{\mathrm{x}} \text { emissions } \\
\left(\mathrm{Tg}\left(\mathrm{NO}_{2}\right) / \mathrm{yr}\right)\end{array}$ & $0.35 / 0.70$ & 0.27 & 0.27 & $<0.005$ & $0.24 / 0.42^{* * * *}$ & $0.17^{* * * * *}$ \\
\hline Fuel consumption $(\mathrm{Tg} / \mathrm{yr})$ & $70 / 140$ & 60 & 60 & 0.4 & $47 / 84$ & 16.8 \\
\hline \multicolumn{7}{|c|}{ Climate effects } \\
\hline $\mathrm{CO}_{2}\left(\mathrm{RF}, \mathrm{mW} \mathrm{m}{ }^{-2}\right)$ & n.a. $/ 6$ & $3.3^{\mathrm{a}}$ & & & $4.1^{* *} /$ n.a. & \\
\hline $\mathrm{H}_{2} \mathrm{O}\left(\mathrm{RF}, \mathrm{mW} \mathrm{m}^{-2}\right)$ & $50(17,150) / 99$ & 23.1 & $40.9^{\mathrm{d}}$ & & $41.9 / 74.1$ & $1.3 *[1.2]$ \\
\hline $\mathrm{O}_{3}\left(\mathrm{RF}, \mathrm{mW} \mathrm{m}^{-2}\right)$ & $-10(-40,10) /-17$ & -2.8 & $-3.2^{c} /-2.5^{d}$ & & $3.8 / 2.1$ & $3.3 *[3.0]$ \\
\hline $\mathrm{CH}_{4}\left(\mathrm{RF}, \mathrm{mW} \mathrm{m}^{-2}\right)$ & n.a. $/ 5$ & -1.6 & & & & $0.08 *[-0.4]$ \\
\hline 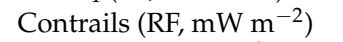 & n.a./-11 & $-0.6^{\mathrm{b}}$ & & & & \\
\hline $\mathrm{BC}\left(\mathrm{RF}, \mathrm{mW} \mathrm{m}^{-2}\right)$ & & & $4.6^{c}$ & & & $-1.3 *[-1.4]$ \\
\hline $\mathrm{SO}_{4}\left(\mathrm{RF}, \mathrm{mW} \mathrm{m}^{-2}\right)$ & & & $-11.4^{\mathrm{c}}$ & & & $-5.2 *[-5.2]$ \\
\hline Total (RF, $\left.\mathrm{mW} \mathrm{m}^{-2}\right)$ & n.a. $/ 82$ & $22(9,29)$ & & 0.1 & & $-2.4 *^{\star}[-3.2]$ \\
\hline Total (temperature, $\mathrm{mK}$ ) & n.a./1.4 & 21 & & $0.08(0.07,0.1)$ & & \\
\hline
\end{tabular}

${ }^{1}$ estimates based on a multi-model mean: six 2D models (AER, CSIRO, GSFC, LLNL, THINAIR, UNIVAQ), three 3D models (LARC, SCTM1, SLIMCAT). ${ }^{2}$ estimates based on mean of E39/C CCM, SLIMCAT CTM, OsloCTM2, ULAQ-CCM. ${ }^{3}$ estimate based on a climate response model, AirClim. ${ }^{4}$ estimates based on CESM/WACCM4 Their emission inventory is based on a study with a similar concept as that used in the IPCC report [55] but not identical to it. ${ }^{5}$ estimates based on GEOS-Chem UCX. ${ }^{a}$ estimate via the $\mathrm{CO}_{2}$ concentration change, not via the radiation code. ${ }^{b}$ estimate from the E39/C CCM, not a model mean; see also [56]. ${ }^{c}$ estimate from the ULAQ-CTM and ULAQ-GCM radiative code, not a model mean. ${ }^{\mathrm{d}}$ model mean as in [9] but different radiative code use; here it is ULAQ-GCM. * estimate read from graphs and thus might not be accurate; number in brackets is the RF based on the experiments where methane is set up as a flux. ${ }^{*}$ total here does not include $\mathrm{CO}_{2}$ and contrails; number in brackets is the RF based on the experiments where methane is set up as a flux. ${ }^{* *}$ provided by [47]. ${ }^{* * *}$ assuming $\mathrm{EI}\left(\mathrm{H}_{2} \mathrm{O}\right)=1.25 \mathrm{~kg} / \mathrm{kg}$. ${ }^{* * * *} \mathrm{EI}\left(\mathrm{H}_{2} \mathrm{O}\right)=1.237 \mathrm{~kg} / \mathrm{kg}$ and $\mathrm{EI}\left(\mathrm{NO}_{\mathrm{x}}\right)=5 \mathrm{~g} / \mathrm{kg}$ are given [10]. ${ }^{* * * * *}$ Value taken from reference but does not match with given $\mathrm{EI}\left(\mathrm{NO}_{\mathrm{x}}\right)$ and fuel consumption. 
Overall, the climate effect of a supersonic fleet is considerably larger than that of a subsonic fleet. According to the IPCC [4], the RF from supersonic aircraft is about five times larger than the RF from the subsonic fleet. However, this factor has significant uncertainty, and it may range from 0 to 16 . According to [9], the near-surface temperature change (in 2100) of supersonic aircraft is around six times as large as the temperature change from subsonic transport. The larger effects arise mainly from the high emission altitude and longer atmospheric lifetimes of $\mathrm{H}_{2} \mathrm{O}$ and other species in the stratosphere. A reduction of the supersonic cruise altitude (by $1.5 \mathrm{~km}$ ) or speed (to Mach 1.6) could reduce the climate effect by around $60 \%$ [9].

\section{Regulatory Issues}

Developments on conventional and supersonic aviation's potential environmental impacts require discussions at an international level. The forerunner of the ICAO's current Committee on Aviation Environmental Protection (ICAO-CAEP) was the CAEE. This Committee had its first major meeting in Montreal in June 1978.

Three working papers were presented at the first CAEE meeting regarding agenda item 4, "Evaluation, on a scientific, technical and economic basis, of the future need for and feasibility of developing international standards for the control of aircraft engine emissions in the stratosphere" [13-15]. These papers set the scene for ICAO-CAEP's future activities on engine emissions regulation and noise limits, many of which are still current.

Worldwide airworthiness authorities such as the US FAA, EASA (the European Aviation Safety Agency) and others actively contribute to the ICAO-CAEP which develops and maintains the international standards relating to the certification of aircraft noise, aeroplane $\mathrm{CO}_{2}$ emissions, fuel venting and aircraft engine emissions: oxides of nitrogen $\left(\mathrm{NO}_{\mathrm{x}}\right)$, unburned hydrocarbons (HC), carbon monoxide (CO), smoke and non-volatile particulate matter (nvPM). Once the standards have been agreed in ICAO, EASA and state-level authorities such as the FAA work to implement them into EU or domestic legislation.

The Convention on the ICAO, also known as the Chicago Convention, is composed of 19 annexes containing the basic standards and recommended practices (SARPs) of international civil aviation. Annex 16 pertains to Environmental Protection [80], and Volume II contains the SARPs regulating aircraft engine emissions. The first publication of Annex 16 Volume II put in place Chapter 3 of Part III ("Chapter 3") which is applicable to turbojet and turbofan engines intended for propulsion at supersonic speeds manufactured from 18 February 1982. Annex 16 Chapter 2 of Part III ("Chapter 2") includes the analogous SARPs for engines of subsonic aeroplanes. The SARPs contained in Chapter 3 were developed in the age of Concorde and based on in-production Olympus engines at that time. Chapter 3 includes regulatory limits for LTO gaseous emissions of NOx, HC and $\mathrm{CO}$ and a visible smoke number standard. The Chapter 3 limits, in particular NOx, for supersonics, are extremely weak by comparison with the current Chapter 2 limits for subsonic aeroplane engines. In addition, Chapter 3 only includes smoke number, whereas Chapter 2 includes new nvPM emission regulations (agreed in CAEP 2019), which will replace the visible smoke number regulation for subsonic engines. Furthermore, it is worth noting that there are no regulations for engine emissions during cruise in either Chapter 2 or 3, based on the premise that a limit or reduction in LTO engine emissions will also translate to a reduction in emissions during cruise. This premise is currently under review within ICAO-CAEP for engines designed for both subsonic and supersonic propulsion.

Concorde was retired from service in 2003, but SST development programmes continued from the 1990s to the early 2000s, and at that time, ICAO-CAEP requested that a review of the emission and noise regulation be undertaken. In February 2007, the CAEP reported that the requirements in Chapter 3 were "outdated and should not be applied to new engine projects". It also indicated that there would need to be significant revisions for any new SSTs, including consideration of in-flight emission impacts. However, the emissions regulation currently remains as written in Chapter 3, and, in the absence of new data and a new stringency setting by the CAEP, these standards remain applicable to any 
new supersonic engines. ICAO-CAEP is currently working on updating the Chapter 3 engine emission SARPs, but this is likely to take some time and more data before this can be agreed and implemented [81].

This is in contrast to noise regulation which in Chapter 12 of Annex 16 was specifically written as applicable to aeroplanes with a type certificate application before 1975, i.e., Concorde. There is currently no ICAO-CAEP noise regulation that would be applicable to new supersonic aeroplanes. Work is on-going in CAEP to gather suitable data for new supersonic aeroplane noise regulation, but again, this is likely to take a number of years. In the absence of an internationally agreed noise regulation for new supersonic aeroplanes, the US issued in April 2020 a notice of proposed rule making for a domestic regulation for supersonic aeroplanes and will apply the emissions regulation based on the outdated Chapter 3 if a product comes forward for certification before the CAEP is able to update it.

In addition to engine emission regulations contained in Volume II, Annex 16 Volume III contains the $\mathrm{CO}_{2}$ emission regulation for subsonic aeroplanes. This ICAO-CAEP SARP was agreed in 2016 with the first $\mathrm{CO}_{2}$ certification completed in May 2021 by EASA. There is no parallel regulation for supersonic aeroplanes. The CAEP is currently gathering data and evidence to first determine a suitable $\mathrm{CO}_{2}$ metric system for an SST aeroplane $\mathrm{CO}_{2}$ standard, and analysing and agreeing on an international regulation of this type is likely to take a number of years. Supersonic cruise is always less fuel-efficient than subsonic cruise for a similar size/weight aeroplane, but the speed of travel is countered by SST proponents as an additional benefit over and above the distance travelled and passenger or payload carried. SST original equipment manufacturers focus on sustainable aviation fuels as a solution to the potential increased carbon intensity of SST compared with subsonic aeroplanes, but it is worth noting that, in a carbon-constrained world, all aviation is likely to require sustainable fuels [82].

\section{Discussion}

Commercial SST causes several environmental concerns, including climate impact, air quality and noise. The atmospheric effects of supersonic aviation have been evaluated in several European and international studies during the last decades. Hence, plans for the introduction of SST at a large scale have led to comprehensive environmental assessments of concepts applied, which relied on detailed knowledge or assumptions on emissions characteristics from propulsion to be combined with comprehensive atmospheric modelling. In order to identify requirements for an overall assessment of the benefits and risks of supersonic aviation comprising the effect on climate, this section discusses the relevance of assumptions on operation concepts, emission characteristics as well as the application of state-of-the-art atmospheric modelling. We discuss the latest knowledge and uncertainties on atmospheric processes and the associated climate impact of supersonic aviation.

From the early beginning of supersonic aviation, strong concerns about possible harmful impacts have been expressed and have led to the establishment of dedicated regulatory working groups. One important driver for these concerns is that concepts of supersonic aviation investigated so far have in common that aircraft are operated at higher altitudes compared to conventional aviation which means that emissions are released in regions of the atmosphere that are potentially more sensitive to their impacts. At the same time, propulsion technologies are required that are able to provide the required thrust, leading to emissions characteristics that may be different to conventional subsonic engines. In recent years, climate concerns and resulting regulations and market-based mitigation measures have become increasingly prevalent for aviation in general and are a major driver in the development of future propulsion technologies. The same development has even been amplified for the case of supersonic aircraft, where viable commercial concepts are currently under development.

An assessment of the climate impact of a future fleet is strongly dependent on assumptions related to the applied airframe concept, routes and the resulting emissions, which have evolved over the last decades. Previous studies investigated aeroplane concepts rang- 
ing from business jets [12] to 500-passenger jetliners [4], which all face different economic and technical challenges and all lack certain implementation schedules. The magnitude of the climate impacts associated with the resulting fleets could be vastly different due to the intended market and routes/frequencies flown. However, e.g., assumptions taken on the emission index of $\mathrm{NO}_{x}$ of a supersonic aircraft vary by a factor of approximately 4 between studies $[9,11]$.

There are several factors that further hinder the direct comparison of climate effect studies that are related to different assumptions on the fleet concept. First, studies of the economic feasibility and the resulting fleet mix in order to achieve a specific transport volume are complicated by the need to consider whether there is any shift of demand between super- and subsonic aviation, as well as by operational flight route restrictions, particularly over land. Hence, some studies consider the effect of supersonic aircraft in isolation, whereas others also include the effect of the expected market-based reduction of subsonic aircraft in response to the introduction of supersonic aircraft (depending on the intended market). This point is particularly critical for a comparison because the climate impact of supersonic emissions also depends in a non-linear fashion on the background atmosphere, which in turn is impacted by the amount of subsonic emissions. Second, assumptions on fleet composition and time horizon of evaluation (in the case of $\mathrm{CO}_{2}$ ) influence the estimates of the climate effect. Each study makes different assumptions on the beginning year of service and subsequent temporal development of flight numbers as well as the background atmosphere during that time period. Other factors are related to different assumptions on emission inventory generation. First, the expected emissions are often relatively crude estimates based on engine designs that are still at an early stage, particularly in those cases where alternative fuels, such as biofuels and hydrogen, are considered and in the case of older studies. Second, the spatial resolution of the created emission inventories differs because expected flight route inventories are based on differing assumptions with regard to whether flying over land at supersonic speed will be possible or, if not, how the multiple components of the routing are optimised. Overall, these differences in emission inventory generation between different studies inhibit the direct quantitative comparison of their results, in addition to the challenge posed by the use of different fleet concepts.

The establishment of regulation has been one important driver for comprehensive assessments during the last decades. The historical analysis shows that regulations for future supersonic aviation depend even more strongly on the available technology than the emission inventory generation does because regulations usually rely on existing technology. Similar challenges would probably also be faced by studies and regulatory aspects addressing LTO emissions and the resulting impact on air quality and public health.

The climate effect of a supersonic fleet is a function of the amount of its emissions $\left(\mathrm{H}_{2} \mathrm{O}\right.$, $\mathrm{CO}_{2}, \mathrm{NO}_{\mathrm{x}}$, aerosols), the time and location of these emissions and subsequent formation of ozone and contrails, influence on other radiative active species and the properties and composition of the background atmosphere in future scenarios. Analysis of the results from different assessment studies shows that the uncertainties among different types of emissions vary greatly due to prevailing uncertainties in modelling of atmospheric and photochemical processes, atmospheric transport and radiative transfer.

Calculation methods for estimating RF due to changes in concentrations of greenhouse gases play an important role in estimating climate effects, which rely either on broadband and narrowband radiative transfer calculations, line-by-line calculation or simplified expressions following IPCC studies [83]. This brings uncertainties to quantitative estimates of climate effects of aerosol, $\mathrm{NO}_{x}$ and $\mathrm{H}_{2} \mathrm{O}$ emissions. Particularly, there is significant uncertainty remaining in the computation of the RF caused by a given ozone perturbation. This issue may be related to the fact that some models do not include perturbations in the upper stratosphere into their RF calculations and could be investigated more closely by separating the effect of short-wave and long-wave RF. In the case of water vapour, the large uncertainty on its RF, amounting to a factor of 2, is considered to be mainly due to 
the radiative transfer modelling. Furthermore, future studies should assure the use of state-of-the-art methods and updates, e.g., Reference [84].

As an input to RF calculations, assessment studies rely on changes in the atmospheric composition of radiatively active species. Climate models that have been used to estimate the effect of changes of radiatively active species induced by a supersonic fleet can be divided into two categories: CCMs and simple climate models (SCM) [85]. While CCMs aim for a comprehensive implementation of relevant physical and chemical processes, SCM offer an efficient implementation enabling, e.g., sensitivity studies to be performed and are usually "tuned" to parent CCMs that have more explicit treatment of physical and chemical processes. However, both models rely on a considerable amount of assumptions (e.g., simplified parametrizations for physical processes) and face various challenges (e.g., limited vertical, horizontal and temporal resolution, limited temporal extent). Particularly, representing heterogeneous chemical reactions that occur on the surfaces of aerosol particles globally and at high resolution is still a challenge for current climate models $[86,87]$. Further research into this heterogeneous chemistry effect is necessary, especially because there is some indication that the magnitude of the climate effect may be comparable to that of water vapour [11]. Other indirect aerosol effects on climate have not yet been investigated by any studies in detail in the context of supersonic aviation. Aerosol-cloud interactions are the least well-understood mechanism in the case of subsonic aviation [7], but the importance of this interaction is likely smaller in the case of supersonic aviation because of the large vertical mixing required before aerosol particles emitted at supersonic cruise altitude reach the troposphere. Overall, comprehensive model evaluations are regularly performed, aiming to identify model capabilities, as well as model limitations. Some limitations have partly been alleviated by computational advances over the last decades, as is illustrated by a study comparing the results of a recent climate model with those of models used two decades ago using the same emission inventories [10], but will never be eliminated completely. Therefore, establishing sensitivities can be a particularly valuable approach [47] Multi-model evaluations have also proven to be valuable in avoiding these shortcomings in the case of subsonic aviation $[7,88,89]$, as well as for the case of supersonic aviation [9].

In summary, quantitative estimates of RF suffer from uncertainties in both the RF computation of aerosols, $\mathrm{NO}_{\mathrm{x}}$ and $\mathrm{H}_{2} \mathrm{O}$ and the modelling of the prerequired compositional changes. Among these, processes related to heterogeneous chemistry on aerosol particles are currently the least well-understood. For this, there are only a few studies, and their results are inconclusive. Nevertheless, the synthesis and comparison of normalized results on water vapour and nitrogen oxide effects presented in Figure 1 provide some valuable insights as to how effects may be investigated in the future. There is some evidence that the RF of water vapour increases in an approximately linear manner with increasing cruise altitude, with a considerable spread in the results. The net forcing from $\mathrm{O}_{3}$, however, cannot be interpreted in such a similarly simplistic manner since the net forcing tends be a scenario-specific combination of subsonic $\mathrm{NO}_{x}$ emissions reductions and supersonic emissions increases. In a number of studies, the net change is not greatly different from zero.

Although the effect of contrails on climate is limited to specific geographic regions for supersonic aviation, uncertainties in this effect are discussed here as supersonic air traffic at low latitudes have the potential to form contrails because of the high tropopause levels. Thus, the latitudinal location of the mission trajectory for a given airframe design will therefore directly affect the climate effect magnitude of contrails. Finally, it might be necessary to explore further the influence of the contrails' inherent characteristics on the RF such as the ice crystal habits, number and size that could be impacted by the stratospheric environment compared to contrails formed in a more stratified environment.

The overall assessments of the climate effect are furthermore relying on physical climate metrics, such as the RF or the mean global near-surface temperature change in a specific year, which answer different scientific questions and are to be regarded with respect to different time horizons. There is no single perfect metric, and its choice depends on the problem being addressed. Thus, the past decisions cannot be treated definitively, 
and any future climate effect assessments should stay open-minded towards a variety of other methodological frameworks. Earlier studies quantified the RF of annual emissions of dedicated supersonic fleets, while we aimed in our study towards provision of additional comparable intensity measures, e.g., RF per amount of fuel burnt. In order to compare distinct technologies, it would also be desirable to provide intensity metrics related to transport volume, e.g., temperature change per RPK. However, as illustrated in this study, a better comparability between different studies would need to be established to enable the usefulness of such metrics.

In summary, a variety of different approaches and assumptions used in previous studies hinders a direct comparison between them while still allowing for general conclusions regarding the climate effect of supersonic flight. Differences encompass design, time frame and market for future supersonic fleets and, subsequently, the emission inventories and climate models. Nevertheless, it is clear that the climate effects of supersonic aviation are fundamentally different from those of subsonic aviation, and the effect per RPK is more severe for supersonics than for subsonics. This fundamental difference is due to the higher flight altitude, placing the aircraft firmly in the stratosphere on most routes, where emissions, particularly water vapour, remain and contribute to RF for years rather than days. This difference, together with the generally higher fuel usage, results in a climate effect that is several times stronger per RPK than that of subsonic aviation $[4,9]$.

\section{Conclusions}

The recent tendency to develop modest-sized fleets of business jets (about 10 passengers) and commercial airliners (up to 100 passengers) rather than the large-scale fleets of large commercial SSTs assumed in the late 1990s and early 2000s is also reflected in the SENECA project.

Among others, flight routes (i.e., location and frequency) and emissions indices for $\mathrm{NO}_{\mathrm{x}}$ and aerosols mostly related to the type of aircraft/engine technology as well as whether aircraft will be permitted to fly at supersonic speeds over land are considered as key in the potential effect of supersonic aviation on climate. Previous research has shown that much value can be gained from carefully formulated sensitivity studies to quantify the magnitude of those parameters.

This review showed that future studies are required to obtain a better evaluation of the climate effects of supersonic aviation. Total climate effects result from the combination and trade-off between individual $\mathrm{CO}_{2}$ and non- $\mathrm{CO}_{2}$ effects, comprising effects from emissions of nitrogen oxides, water vapour and aerosols. Several parts of the computation still exhibit important uncertainty, including those associated with heterogeneous chemistry and the radiative transfer modelling for ozone, water vapour, aerosols and contrails. The largest uncertainties are likely to be associated with the impact of aerosols. However, in the light of the expected increased usage of sustainable aviation fuels, the large dependence of aerosol emissions on fuel composition should also be considered in future investigations.

Author Contributions: Conceptualization, S.M. and D.S.L.; investigation, S.M., D.S.L., R.R.D.L., L.L., B.O., A.S., R.N.T. and E.T.; writing—original draft preparation, S.M., D.S.L., R.R.D.L., L.L., B.O., A.S., R.N.T. and E.T.; writing-review and editing, S.M., D.S.L., R.R.D.L., L.L., B.O., A.S., R.N.T. and E.T.; visualization, A.S. All authors have read and agreed to the published version of the manuscript.

Funding: This research was funded by the European Union's Horizon 2020 research and innovation programme under grant agreement No. 101006742, project SENECA ((LTO) Noise and Emissions of Supersonic Aircraft).

Informed Consent Statement: Not applicable.

Data Availability Statement: Not applicable.

Acknowledgments: We would like to thank Corinne Marizy, Volker Grewe and Pénélope Leyland for providing additional information on the SCENIC project and Arthur Schady for a thorough internal review.

Conflicts of Interest: The authors declare no conflict of interest. 
Abbreviations

\begin{tabular}{|c|c|}
\hline AESA & Atmospheric Effects of Stratospheric Aircraft Project \\
\hline AirClim & climate response model \\
\hline ASCENT & Aviation Sustainability Centre \\
\hline $\mathrm{BC}$ & black carbon \\
\hline CAEE & Committee on Aviation Engine Emissions \\
\hline CAEP & Committee on Aviation Environmental Protection \\
\hline CIAP & Climatic Impact Assessment Program \\
\hline CCM & climate-chemistry model \\
\hline CESM/WACCM4 & $\begin{array}{l}\text { Community Earth System Model/Whole Atmosphere Community } \\
\text { Climate Model version } 4\end{array}$ \\
\hline COMESA & Committee on Meteorological Effects of Stratospheric Aircraft \\
\hline COVOS & Comité d'Etudes sur les Conséquences des Vols Stratosphériques \\
\hline CTM & chemical transport model \\
\hline EASA & European Aviation Safety Agency \\
\hline ECHAM & European Centre for Medium-Range Weather Forecast (ECMWF) Hamburg GCM \\
\hline EI & emission index \\
\hline ERF & effective radiative forcing \\
\hline $\mathrm{E} 39 / \mathrm{C}$ & ECHAM4/L39 chemistry model from the German Aerospace Center \\
\hline FAA & Federal Aviation Administration \\
\hline GCM & general circulation model \\
\hline GEOS-Chem & Goddard Earth Observing System chemistry model \\
\hline HAPP & High Altitude Pollution Program \\
\hline $\mathrm{HC}$ & unburned hydrocarbons \\
\hline HISAC & environmentally friendly high-speed aircraft \\
\hline HSRP & High-Speed Research Program \\
\hline ICAO & International Civil Aviation Organization \\
\hline IPCC & Intergovernmental Panel on Climate Change \\
\hline LTO & Landing and Take-Off \\
\hline MDO & multidisciplinary design optimisation \\
\hline MOREandLESS & $\begin{array}{l}\text { MDO and REgulations for Low-boom and Environmentally Sustainable } \\
\text { Supersonic aviation }\end{array}$ \\
\hline NAS & National Academy of Sciences \\
\hline NASA & National Aeronautics and Space Administration \\
\hline $\mathrm{NO}_{x}$ & nitrogen oxides $\left(\mathrm{NO}+\mathrm{NO}_{2}\right)$ \\
\hline nvPM & non-volatile particulate matter \\
\hline OsloCTM2 & model from the University of Oslo \\
\hline PCC & persistent contrail condition \\
\hline RF & radiative forcing \\
\hline RPK & revenue passenger kilometre \\
\hline SARP & standards and recommended practices \\
\hline SCENIC & scenario of aircraft emissions and impact studies on atmosphere and climate \\
\hline SCM & simple climate model \\
\hline SENECA & (LTO) noiSe and EmissioNs of supErsoniC Aircraft \\
\hline SLIMCAT & model from the University of Cambridge \\
\hline SST & supersonic transport \\
\hline UARP & Upper Atmospheric Research Program \\
\hline ULAQ-CCM & chemistry climate model of the University of L'Aquila \\
\hline ULAQ-CTM & chemical transport model of the University of L'Aquila \\
\hline ULAQ-GCM & general circulation model of the University of L'Aquila \\
\hline $\mathrm{UT} / \mathrm{LS}$ & upper troposphere/lower stratosphere \\
\hline UV & ultraviolet \\
\hline
\end{tabular}

\section{References}

1. Johnston, H. Reduction of stratospheric ozone by nitrogen oxide catalysts from SST exhaust. Science 1971, 173, 517-522. [CrossRef] [PubMed]

2. Crutzen, P.J. SST's: A threat to the Earth's ozone shield. Ambio 1972, 1, 41-51. 
3. Tuck, A.F. Perspective on aircraft in the stratosphere: 50 years from COMESA through the ozone hole to climate. Q. J. R. Meteorolog. Soc. 2021, 147, 713-727. [CrossRef]

4. IPCC. Aviation and the Global Atmosphere; Penner, J.E., Lister, D.H., Griggs, D.J., Dokken, D.J., McFarland, M., Eds.; Cambridge University Press: Cambridge, UK, 1999; p. 373.

5. Lee, D.S.; Pitari, G.; Grewe, V.; Gierens, K.; Penner, J.E.; Petzold, A.; Prather, M.J.; Schumann, U.; Bais, A.; Berntsen, T.; et al. Transport impacts on atmosphere and climate: Aviation. Atmos. Environ. 2010, 44, 4678-4734. [CrossRef] [PubMed]

6. Holmes, C.D.; Tang, Q.; Prather, M.J. Uncertainties in climate assessment for the case of aviation NO. Proc. Natl. Acad. Sci. USA 2011, 108, 10997-11002. [CrossRef]

7. $\quad$ Lee, D.S.; Fahey, D.W.; Skowron, A.; Allen, M.R.; Burkhardt, U.; Chen, Q.; Doherty, S.J.; Freeman, S.; Forster, P.M.; Fuglestvedt, J.; et al. The contribution of global aviation to anthropogenic climate forcing for 2000 to 2018. Atmos. Environ. 2021, 244, 117834. [CrossRef] [PubMed]

8. Kinnison, D.; Brasseur, G.P.; Baughcum, S.L.; Zhang, J.; Wuebbles, D. The impact on the ozone layer of a potential fleet of civil hypersonic aircraft. Earth's Future 2020, 8, e2020EF001626. [CrossRef]

9. Grewe, V.; Stenke, A.; Ponater, M.; Sausen, R.; Pitari, G.; Iachetti, D.; Rogers, H.; Dessens, O.; Pyle, J.; Isaksen, I.S.A.; et al. Climate impact of supersonic air traffic: An approach to optimize a potential future supersonic fleet-results from the EU-project SCENIC. Atmos. Chem. Phys. 2007, 7, 5129-5145. [CrossRef]

10. Zhang, J.; Wuebbles, D.; Kinnison, D.; Baughcum, S.L. Potential impacts of supersonic aircraft emissions on ozone and resulting forcing on climate. An update on historical analysis. J. Geophys. Res. Atmos. 2021, 126, e2020JD034130. [CrossRef]

11. Speth, R.L.; Eastham, S.D.; Fritz, T.M.; Sanz-Morére, I.; Agarwal, A.; Prashanth, P.; Allroggen, F.; Barrett, S.R.H. Global Environmental Impact of Supersonic Cruise Aircraft in the Stratosphere; NASA Glenn Research Center: Cleveland, OH, USA, 2021.

12. Grewe, V.; Plohr, M.; Cerino, G.; Di Muzio, M.; Deremaux, Y.; Galerneau, M.; de Saint Martin, P.; Chaika, T.; Hasselrot, A.; Tengzelius, U.; et al. Estimates of the climate impact of future small-scale supersonic transport aircraft-results from the HISAC EU-project. Aeronaut. J. 2010, 114, 199-206. [CrossRef]

13. Committee on Aircraft Engine Emissions. Aircraft pollution at high altitudes. In Proceedings of the First Meeting of the Committee on Aircraft Engine Emissions (CAEE-WP/11), Montreal, QC, Canada, 12-22 June 1978.

14. Committee on Aircraft Engine Emissions. Stratospheric aircraft pollution. In Proceedings of the First Meeting of the Committee on Aircraft Engine Emissions (CAEE-WP/22), Montreal, QC, Canada, 12-22 June 1978.

15. Committee on Aircraft Engine Emissions. Aircraft engine emissions in the stratosphere. In Proceedings of the First Meeting of the Committee on Aircraft Engine Emissions (CAEE-WP/24), Montreal, QC, Canada, 12-22 June 1978.

16. Carisosica, S.A.; Lock, J.W.; Boyd, I.D.; Lewis, M.J.; Hallion, R.P. Commerical Development of Civilian Supersonic Aircraft. IDA Science and Tecnology Policy Institute, IDA Document D-10845. 2019. Available online: https://www.ida.org/-/media/feature/ publications/c/co/commercial-development-of-civilian-supersonic-aircraft/d-10845.ashx (accessed on 12 August 2021).

17. Kowalok, M.E. Common threads: Research lessons from acid rain, ozone depletion, and global warming. Environ. Sci. Policy Sustain. Dev. 1993, 35, 12-38. [CrossRef]

18. Wilson, C.M.; Matthews, W.H. Man's Impact on the Global Environment. Report of the Study of Critical Environmental Problems (SCEP); MIT Press: Cambridge, MA, USA, 1970.

19. Harrison, H. Stratospheric ozone with added water vapor: Influence of high-altitude aircraft. Science 1970, 170, 734-736. [CrossRef] [PubMed]

20. Crutzen, P.J. The influence of nitrogen oxides on the atmospheric ozone content. Q. J. R. Met. Soc. 1970, 96, 320-325. [CrossRef]

21. Crutzen, P.J. Ozone production rates in an oxygen-hydrogen-nitrogen oxide atmosphere. J. Geophys. Res. 1971, 76, 7311-7327. [CrossRef]

22. SMIC. Inadvertent Climate Modification, Report of the Study of Man's Impact on Climate. Science 1972, $176,38$.

23. CTAB. Environmental Aspects of the Supersonic Transport: A Recommended Program for Research and Measurement; Report to the Commerce Technical Advisory Board; U.S. Department of Commerce: Washington, DC, USA, 1972.

24. Australian Academy of Sciences. Atmospheric Effects of Supersonic Aircraft; Technical Report No. 15; Australian Academy of Science: Canberra, Australia, 1972.

25. U.S. Government Print. The Supersonic Transport; U.S. Government Print: Washington, DC, USA, 1971.

26. National Academy of Sciences. Biological Impacts of Increased Intensities of Solar Ultraviolet Radiation; The National Academies Press: Washington, DC, USA, 1973.

27. Johnston, H.S. A turning point. Scientist 1996, 10, 9-12.

28. Grobecker, A.J.; Coroniti, S.C.; Cannon, R.H., Jr. Report of Findings: The Effects of Stratospheric Pollution by Aircraft. Climatic Impact Assessment Program Report DOT-TSC-75-50; U.S. Department of Transportation: Washington, DC, USA, 1974.

29. Wayne, R.P. Chemistry of Atmospheres; Oxford University Press: Oxford, UK, 2000.

30. Morrisette, P.M. The evolution of policy responses to stratospheric ozone depletion. Nat. Resour. J. 1989, $29,793-820$.

31. National Academy of Sciences. Environmental Impact of Stratospheric Flight: Biological and Climatic Effects of Aircraft Emissions in the Stratosphere; The National Academies Press: Washington, DC, USA, 1975.

32. Committee on the Meteorological Effects of Stratospheric Aircraft (COMESA). The Report of the Committee on Meteorological Effects of Stratospheric Aircraft; United Kingdom Meteorological Office: Bracknell, UK, 1976; Volumes 1 and 2. 
33. Comité d'Études sur les Conséquences des Vols Stratosphèriques (COVOS). Rapport Finale, COVOS, Activités 1972-1976; Société Météorologique de France: Boulogne, France, 1976.

34. Broderick, A.J. Stratospheric effects from aviation. J. Aircr. 1978, 15, 643-653. [CrossRef]

35. Crutzen, P.A. Discussion of the chemistry of some minor constituents in the stratosphere and troposphere. Pure Appl. Geophys. 1973, 106, 1385-1399. [CrossRef]

36. Oliver, R.C.; Bauer, E.; Wasylkiwskyj, W. Recent Developments in the Estimation of Potential Effects of High Altitude Aircraft Emissions on Ozone and Climate; Technical Report No. AD-A-063586; Institute for Defense Analyses: Arlington, VA, USA, 1978.

37. Johnston, H.S.; Prather, M.J.; Watson, R.T. The Atmospheric Effects of Stratospheric Aircraft: A Topical Review; NASA: Washington, DC, USA, 1991.

38. Douglass, A.R.; Carroll, M.A.; DeMore, W.B.; Holton, J.R.; Isaksen, I.S.A.; Johnston, H.S.; Ko, M.K. The Atmospheric Effects of Stratospheric Aircraft: A Current Consensus; NASA: Washington, DC, USA, 1991.

39. Johnston, H.S.; Kinnison, D.E.; Wuebbles, D.J. Nitrogen oxides from high-altitude aircraft: An update of potential effects on ozone. J. Geophys. Res. Atmos. 1989, 94, 16351-16363. [CrossRef]

40. Prather, M.J. (Ed.) The Atmospheric Effects of Stratospheric Aircraft: A First Program Report; National Aeronautics and Space Administration, Office of Management, Scientific and Technical Information Program: Washington, DC, USA, 1992 ; Volume 1272.

41. Stolarski, R.S.; Wesoky, H.L. The Atmospheric Efects of Stratospheric Aircraft: A Second Program Report; NASA: Washington, DC, USA, 1993.

42. Stolarski, R.S.; Wesoky, H.L. The Atmospheric Effects of Stratospheric Aircraft: A Third Program Report; NASA: Washington, DC, USA, 1993.

43. Albritton, D.L.; Brune, W.H.; Douglass, A.R.; Dryer, F.L.; Ko, M.K.W.; Koib, C.E.; Miake-Lye, R.C.; Prather, M.J.; Ravishankara, A.R.; Rood, R.B.; et al. The Atmospheric Effects of Stratospheric Aircraft: Interim Assessment Report of the NASA High-Speed Research Program; NASA: Washington, DC, USA, 1993.

44. National Research Council. Atmospheric Effects of Stratospheric Aircraft: An Evaluation of NASA's Interim Assessment; National Academy Press: Washington, DC, USA, 1994; Volume 196324.

45. Stolarski, R.S.; Wesoky, H.L. The Atmospheric Effects of Stratospheric Aircraft: A Fourth Program Report; NASA: Washington, DC, USA, 1995.

46. National Research Council. A Review of NASA's 'Atmospheric Effects of Stratospheric Aircraft' Project; The National Academies Press: Washington, DC, USA, 1999.

47. Zhang, J.; Wuebbles, D.; Kinnison, D.; Baughcum, S.L. Stratospheric Ozone and Climate Forcing Sensitivity to Cruise Altitudes for Fleets of Potential Supersonic Transport Aircraft. J. Geophys. Res. Atmos. 2021, 126, e2021JD034971. [CrossRef]

48. Boom-Overture. Available online: https://boomsupersonic.com/overture (accessed on 12 August 2021).

49. The Spike S-512 Supersonic Business Jet. Available online: https://www.spikeaerospace.com/s-512-supersonic-jet/ (accessed on 12 August 2021).

50. Supersonic Business Jet Developer Aerion Folds. Available online: https://www.flightglobal.com/business-aviation/supersonicbusiness-jet-developer-aerion-folds/143867.article (accessed on 12 August 2021).

51. Berton, J.J.; Huff, D.L.; Geiselhart, K.A.; Seidel, J.A. Supersonic Technology Concept Aeroplanes for Environmental Studies. In Proceedings of the AIAA SciTech Forum and Exposition, Orlando, FL, USA, 6-10 January 2020. Available online: https: //ntrs.nasa.gov/api/citations/20200000513/downloads/20200000513.pdf (accessed on 21 October 2021).

52. Aviation Week. TsAGI Reveals Supersonic Commercial Aircraft Demonstrator. Available online: https://aviationweek.com/airtransport/aircraft-propulsion/tsagi-reveals-supersonic-commercial-aircraft-demonstrator (accessed on 21 October 2021).

53. Rutherford, D.; Graver, B.; Chen, C. Noise and Climate Impacts of an Unconstrained Commercial Supersonic Network; Working Paper 2019-02; The International Council on Clean Transportation: Washington, DC, USA, 2019.

54. Mavris, D.; Crossley, W.; Tai, J.; DeLaurentis, D. Project 010 Aircraft Technology Modeling and Assessment; Technical Report; Georgia Institute of Technology and Purdue University: Atlanta, GA, USA, 2019.

55. Baughcum, S.L.; Henderson, S.C. Aircraft Emission Scenarios Projected in Year 2015 for the NASA Technology Concept Aircraft (TCA) High Speed Civil Transport; Technical Report No. 207635; National Aeronautics and Space Administration, Langley Research Center: Hampton, VA, USA, 1998.

56. Stenke, A.; Grewe, V.; Pechtl, S. Do supersonic aircraft avoid contrails? Atmos. Chem. Phys. 2008, 8, 955-967. [CrossRef]

57. Kharina, A.; MacDonald, T.; Rutherford, D. Environmental Performance of Emerging Supersonic Transport Aircraft; The International Council On Clean Transportation: Washington, DC, USA, 2018.

58. Lin, X.; Trainer, M.; Liu, S.C. On the nonlinearity of the tropospheric ozone production. J. Geophys. Res. Atmos. 1988, 93, 15879-15888. [CrossRef]

59. Søvde, O.A.; Gauss, M.; Isaksen, I.S.A.; Pitari, G.; Marizy, C. Aircraft pollution-A futuristic view. Atmos. Chem. Phys. 2007, 7, 3621-3632. [CrossRef]

60. Lary, D.J. Catalytic destruction of stratospheric ozone. J. Geophys. Res. Atmos. 1997, 102, 21515-21526. [CrossRef]

61. Forster, P.M.; Shine, K.P. Radiative forcing and temperature trends from stratospheric ozone changes. J. Geophys. Res. Atmos. 1997, 102, 10841-10855. [CrossRef]

62. Pitari, G.; Iachetti, D.; Mancini, E.; Montanaro, V.; Luca, N.D.; Marizy, C.; Dessens, O.; Rogers, H.; Pyle, J.; Grewe, V.; et al. Radiative forcing from particle emissions by future supersonic aircraft. Atmos. Chem. Phys. 2008, 8, 4069-4084. [CrossRef] 
63. Tie, X.; Brasseur, G. The response of stratospheric ozone to volcanic eruptions: Sensitivity to atmospheric chlorine loading. Geophys. Res. Lett. 1995, 22, 3035-3038. [CrossRef]

64. Pitari, G.; Aquila, V.; Kravitz, B.; Robock, A.; Watanabe, S.; Cionni, I.; De Luca, N.; Di Genova, G.; Mancini, E.; Tilmes, S. Stratospheric ozone response to sulfate geoengineering: Results from the Geoengineering Model Intercomparison Project (GeoMIP). J. Geophys. Res. Atmos. 2014, 119, 2629-2653. [CrossRef]

65. Tilmes, S.; Garcia, R.R.; Kinnison, D.E.; Gettelman, A.; Rasch, P.J. Impact of geoengineered aerosols on the troposphere and stratosphere. J. Geophys. Res. Atmos. 2009, 114. [CrossRef]

66. Solomon, S.; Rosenlof, K.H.; Portmann, R.W.; Daniel, J.S.; Davis, S.M.; Sanford, T.J.; Plattner, G.K. Contributions of stratospheric water vapor to decadal changes in the rate of global warming. Science 2010, 327, 1219-1223. [CrossRef] [PubMed]

67. Gettelman, A. The evolution of aircraft emissions in the stratosphere. Geophys. Res. Lett. 1998, 25, 2129e2132. [CrossRef]

68. Pitari, G.; Mancini, E. Climatic impact of future supersonic aircraft: Role of water vapour and ozone feedback on circulation. Phys. Chem. Earth Part C 2001, 26, 571-576. [CrossRef]

69. Kawa, S.R.; Anderson, J.G.; Baughcum, S.L.; Brock, C.A.; Brune, W.H.; Cohen, R.C.; Kinnison, D.E.; Newman, P.A.; Rodriguez, J.M.; Stolarski, R.S.; et al. Assessment of the Effects of High-Speed Aircraft in the Stratosphere: 1998 (National Aeronautics and Space Administration Report); Technical Report No. 1999-209237; National Academies Press: Washington, DC, USA, 1999.

70. Wilcox, L.J.; Shine, K.P.; Hoskins, B.J. Radiative forcing due to aviation water vapour emissions. Atmos. Environ. $2012,63,1-13$.

71. Frömming, C.; Ponater, M.; Dahlmann, K.; Grewe, V.; Lee, D.S.; Sausen, R. Aviation-induced radiative forcing and surface temperature change in dependency of the emission altitude. J. Geophys. Res. Atmos. 2012, 117, 9717-9736. [CrossRef]

72. Lim, L.L.; Lee, D.S.; Owen, B.; Skowron, A.; Matthes, S.; Burkhardt, U.; Dietmüller, S.; Pitari, G.; Di Genova, G.; Iachetti, D.; et al. REACT4C: Simplified mitigation studies. In Proceedings of the TAC Conference, Bad Kohlgrub, Germany, 22-25 June 2015; pp. 181-185.

73. Forster, C.; Stohl, A.; James, P.; Thouret, V. The residence times of aircraft emissions in the stratosphere using a mean emission inventory and emissions along actual flight tracks. J. Geophys. Res. 2003, 108, 8524. [CrossRef]

74. Myhre, G.; Kvalevåg, M.; Raedel, G.; Cook, J.; Shine, K.P.; Clark, H.; Karcher, F.; Markowicz, K.; Kardas, A.; Wolkenberg, P.; et al. Intercomparison of radiative forcing calculations of stratospheric water vapour and contrails. Meteorol. Z. 2009, 18, 585. [CrossRef]

75. Matthes, S.; Lim, L.; Burkhardt, U.; Dahlmann, K.; Dietmüller, S.; Grewe, V.; Haslerud, A.S.; Hendricks, J.; Owen, B.; Pitari, G.; et al. Mitigation of non- $\mathrm{CO}_{2}$ aviation's climate impact by changing cruise altitudes. Aerospace 2021, 8, 36. [CrossRef]

76. Kärcher, B. Formation and radiative forcing of contrail cirrus. Nat. Commun. 2018, 9, 1824. [CrossRef] [PubMed]

77. Bräuer, T.; Voigt, C.; Sauer, D.; Kaufmann, S.; Hahn, V.; Scheibe, M.; Schlager, H.; Huber, F.; Le Clercq, P.; Moore, R.; et al. Reduced ice number concentrations in contrails from low aromatic biofuel blends. Atmos. Chem. Phys. Discuss. 2021, 21, 16817-16826. [CrossRef]

78. Dessens, O.; Rogers, H.L.; Pyle, J.A. A change in the calculated impact of supersonic aircraft $\mathrm{NO}_{\mathrm{x}}$ emissions on the atmosphere. Aeronaut. J. 2007, 111, 311-314. [CrossRef]

79. Grewe, V.; Stenke, A. AirClim: An efficient tool for climate evaluation of aircraft technology. Atmos. Chem. Phys. 2008, 8, 4621-4639. [CrossRef]

80. Environment Publications. Available online: https://www.icao.int/environmental-protection/Pages/environment-publications. aspx (accessed on 12 August 2021).

81. Committee on Aviation Environmental Protection Report (Doc 10126). In Proceedings of the 11th Meeting of the Committee on Aviation Environmental Protection, Montreal, QC, Canada, 4-15 February 2019.

82. Russel, R.; Maurice, L.; Devine, R. Supersonic flight and sustainability: A new horizon. Bridge 2020, 50, $28-33$.

83. Ramaswamy, V. Radiative forcing of climate change. In Climate Change 2001: The Scientific Basis; Houghton, J.T., Ed.; Cambridge University Press: New York, NY, USA, 2001; pp. 349-416.

84. Etminan, M.; Myhre, G.; Highwood, E.J.; Shine, K.P. Radiative forcing of carbon dioxide, methane, and nitrous oxide: A significant revision of the methane radiative forcing. Geophys. Res. Lett. 2016, 43, 12-614. [CrossRef]

85. Grewe, V.; Stenke, A.; Plohr, M.; Korovkin, V.D. Climate functions for the use in multi-disciplinary optimisation in the pre-design of supersonic business jet. Aeronaut. J. 2010, 114, 259-269. [CrossRef]

86. Kremser, S.; Thomason, L.W.; von Hobe, M.; Hermann, M.; Deshler, T.; Timmreck, C.; Toohey, M.; Stenke, A.; Schwarz, J.P.; Weigel, R.; et al. Stratospheric aerosol-Observations, processes, and impact on climate. Rev. Geophys. 2016, 54, $278-335$. [CrossRef]

87. Righi, M.; Hendricks, J.; Lohmann, U.; Beer, C.G.; Hahn, V.; Heinold, B.; Heller, R.; Krämer, M.; Ponater, M.; Rolf, C.; et al. Coupling aerosols to (cirrus) clouds in the global EMAC-MADE3 aerosol-climate model. Geosci. Model Dev. 2020, 13, 1635-1661. [CrossRef]

88. Lee, D.S.; Fahey, D.W.; Forster, P.M.; Newton, P.J.; Wit, R.C.; Lim, L.L.; Owen, B.; Sausen, R. Aviation and global climate change in the 21st century. Atmos. Environ. 2009, 43, 3520-3537. [CrossRef] [PubMed]

89. Søvde, O.A.; Matthes, S.; Skowron, A.; Iachetti, D.; Lim, L.; Owen, B.; Hodnebrog, Ø.; Di Genova, G.; Pitari, G.; Lee, D.S.; et al. Aircraft emission mitigation by changing route altitude: A multi-model estimate of aircraft $\mathrm{NO}_{x}$ emission impact on $\mathrm{O}_{3}$ photochemistry. Atmos. Environ. 2014, 95, 468-479. [CrossRef] 